\title{
DÜBLIN
}

Technological University Dublin

ARROW@TU Dublin

\section{Reducing In-Stent Restenosis through Novel Stent Flow Field Augmentation}

\author{
Eoin Murphy \\ Technological University Dublin, eoin.murphy@tudublin.ie \\ Fergal Boyle \\ Dublin Institute of Technology, fergal.boyle@tudublin.ie
}

Follow this and additional works at: https://arrow.tudublin.ie/biodevart

Part of the Biomedical Engineering and Bioengineering Commons

\section{Recommended Citation}

Murphy, E., Boyle, F. (2012) Reducing in-stent restenosis through novel stent flow field augmentation. Cardiovascular Engineering and Technology, Vol. 3, no. 4, pp. 353-373. doi:10.1007/s13239-012-0109-3

This Article is brought to you for free and open access by the Biomedical Devices and Assistive Technology Research Group at ARROW@TU Dublin. It has been accepted for inclusion in Articles by an authorized administrator of ARROW@TU Dublin. For more information, please contact arrow.admin@tudublin.ie, aisling.coyne@tudublin.ie, gerard.connolly@tudublin.ie. Funder: DIT 

Field Augmentation Associate Editor Bruce H. KenKnight oversaw the review of this article.

\author{
Eoin A. Murphy and Fergal J. Boyle \\ Department of Mechanical Engineering, Dublin Institute of Technology, Bolton Street, Dublin 1, Ireland \\ (Received 30 May 2012; accepted 25 September 2012)
}

\begin{abstract}
In-stent restenosis (ISR), manifested as a re-narrowing of the arterial lumen post-implantation of a stent, is a detrimental limitation of stent technology. Understanding and consequently devising ways of reducing the frequency of ISR has been a continuing goal of research into improved stent designs. The biological processes that can lead to ISR have been found to be partially flow dependent with the local hemodynamics at the arterial wall of crucial importance. This paper investigates these biological processes and their instigating factors. Furthermore, the history and theory behind three stent technologies which endeavour to reduce ISR rates through stent flow field augmentation are presented: a flow divider which increases the blood-flow velocity and consequently the wall shear stress through a stented region, and two novel stent technologies which induce helical flow that mimics the natural blood flow present in healthy arteries. This paper serves as a thorough introduction to both the investigation of ISR, particularly the influence of the local hemodynamics, and to the three novel stent technologies which aim to reduce ISR rates.
\end{abstract}

Keywords-In-stent restenosis, Wall shear stress, Helical flow, Flow divider, Helical stent, Helical-ridge insert.

\section{INTRODUCTION}

Cardiovascular disease (CVD) is currently one of the leading causes of death in the developed world. In a report published by the American Heart Association (AHA) in February 2011 it was stated that CVD accounted for $33.6 \%(813,804)$ of all $2,243,712$ deaths in the US in $2007 .{ }^{114}$ CVD encompasses a spectrum of diseases which affect the cardiovascular system including hypertension, stroke and coronary artery disease (CAD). CAD accounted for $49.9 \%$ of all

Address correspondence to Eoin A. Murphy, Department of Mechanical Engineering, Dublin Institute of Technology, Bolton Street, Dublin 1, Ireland. Electronic mail: eoin.murphy@dit.ie deaths due to CVD in the US in $2007 .{ }^{114}$ In cases of CAD, atherosclerotic lesions, typically formed in the coronary arteries over the course of decades, narrow the arterial lumen area, thereby reducing the flow of blood, and consequently oxygen and nutrients, to tissue cells downstream.

Balloon angioplasty was developed by Charles Dotter in the $1960 \mathrm{~s}^{31}$ as a minimally invasive treatment for the arterial narrowing caused by atherosclerotic lesions in the peripheral arteries, and later in the $1970 \mathrm{~s}$ it was applied to renal, coronary and iliac arteries by Grüntzig and co-workers. ${ }^{49-51}$ Re-blockage of a treated coronary artery following this procedure, known as restenosis, was reported in $30-60 \%$ of patients, ${ }^{44}$ with these patients consequently needing re-treatment with either percutaneous methods or bypass surgery. Restenosis following balloon angioplasty is attributed to three key responses: acute elastic recoil, negative wall remodelling (reduction in lumen area without a change in wall mass) and arterial wall thickening into the lumen (due to an increase in the number of cells within the arterial wall).

Bare metal stents (BMS) were incorporated into the angioplasty procedure in the 1990 s to serve as a rigid scaffold, thus eliminating elastic recoil and reducing wall remodelling, ${ }^{56}$ with some cases of positive remodelling reported. ${ }^{102}$ Even though stenting reduced restenosis rates to between 22 and $32 \%,{ }^{37,44,126}$ it still continued to be a burden. Restenosis with stents, known as in-stent restenosis (ISR), is mostly due to arterial wall thickening. Understanding and consequently devising ways of reducing the frequency of ISR has been a continuing goal of research into improved stent designs. From this research drug-eluting stents (DES) were developed which use anti-proliferative, immunosuppressive, pro-healing and anti-inflammatory drugs in an attempt to prevent ISR. DESs have 
80 proved effective, with ISR rates at six-month follow-up 81 as low as $2.6-10.1 \%{ }^{137}$ and consequently DESs sur82 passed BMSs as the preferred stent choice with $70-80 \%$ 83 of stent procedures in the US carried out with DESs by 84 mid-2009. ${ }^{41,78}$ However, ISR is still a problem along 85 with stent thrombosis, and delayed re-endothelialisa86 tion (re-growth of the endothelium) due to the anti87 proliferative properties of some DES drugs. ${ }^{42}$ stent implantation and how these can lead to ISR through the biological processes they instigate in the arterial wall. "Flow-Augmentation Stent Devic" section reviews the history and theory behind the three stent flow field augmentation devices, followed by a discussion and conclusions in "Discussion" and "Conclusion" sections, respectively.

\section{IN-STENT RESTENOSIS}

\section{Introduction}

A diagram of a healthy arterial wall is given in Fig. 1; however, the exact composition of a diseased artery deviates from this ideal form. Stent implantation has three effects on a treated artery: it induces structural injury, introduces a foreign body and alters the local hemodynamics. These three effects instigate and influence four interacting biological processes which can lead to re-narrowing of the stented artery, known as ISR. ISR is defined as angiographic evidence of a loss of greater than $50 \%$ of the lumen diameter post intervention. $^{95}$

Structural injury is inflicted on the arterial wall during the implantation procedure. The stent and balloon denude most of the endothelium on contact, exposing the underlying collagen fibres and leaving some damaged endothelial cells (ECs) directly adjacent to the stent struts. ${ }^{116}$ Stent implantation stretches, and therefore stresses, the arterial wall and as a result the cellular structure of vascular smooth muscle cells (VSMCs) present in the media can be disrupted, and the internal elastic lamina (IEL) and the media can rupture. Atherosclerotic lesions present at an implantation site are inelastic and frequently split rather than

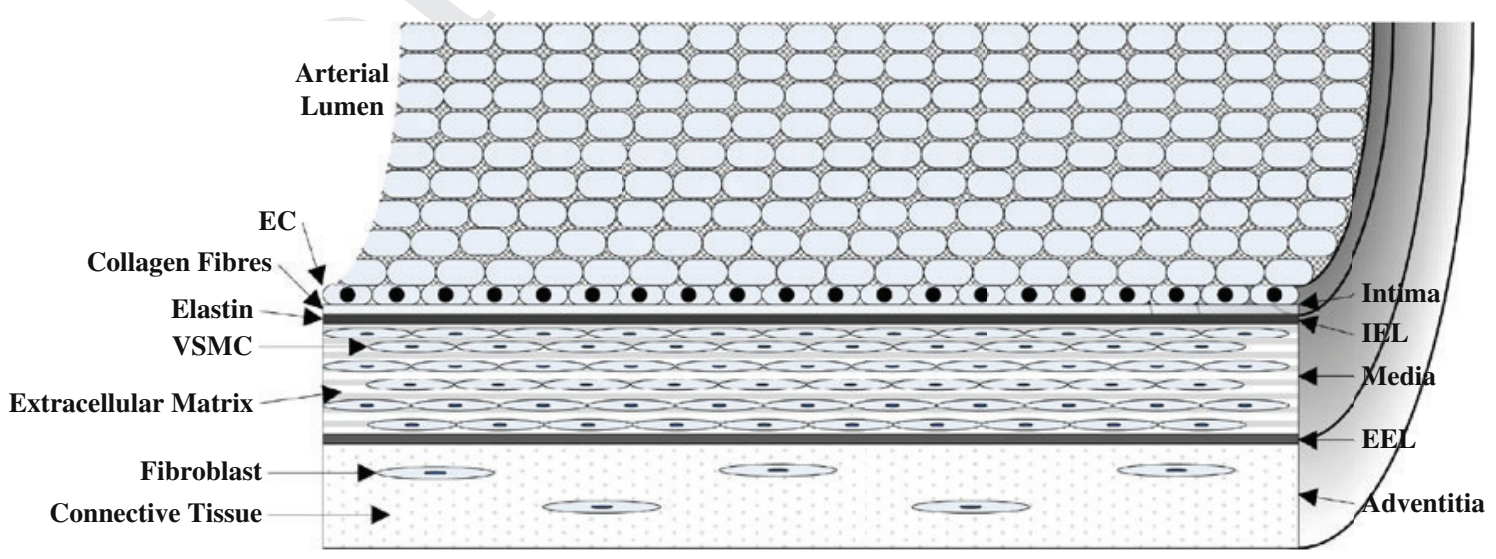

FIGURE 1. Simplified diagram of a healthy artery showing the separate layers and the main cellular components and fibres. Abbreviations: internal elastic lamina (IEL), external elastic lamina (EEL), endothelial cell (EC) and vascular smooth muscle cell (VSMC). 
148 stretch upon stent implantation. This combined dam-

age induces a healing response within the arterial wall.

When a stent is inserted in the artery its nonbiological surface composition induces a foreign-body response. This response is dependent on properties such as the biocompatibility of the surface material and the surface roughness, along with the existence of contaminants on the surface of the stent. The surface material and roughness of a stent affects how quickly the arterial wall heals over the struts. Contaminants, such as powder from surgical gloves, have been found on a stent surface due to handling before catheter insertion. ${ }^{4}$ Improved biocompatibility of stent materials and rinsing of stents before implantation reduce the foreign-body response; however, the non-biological nature of stents instigates cells and proteins in the body to react to what they perceive as a foreign invader.

When a stent is implanted in a diseased artery the geometry of the artery is altered, which in turn augments the local hemodynamics. The lesion is compressed out against the arterial wall, clearing the lumen blockage and reinstating blood flow. The stented artery adopts a new geometry based on the stent strut configuration with the struts pressed against the arterial wall and prolapsed tissue between them. In some cases of over-inflation of the balloon, a step-up phenomenon at the ends of the stent can occur, creating recirculation zones at these points. Also, some degree of longitudinal straightening by stent implantation has been reported in curved arteries. ${ }^{52}$ These changes are a deviation from the smooth surface presented to the blood flow by a healthy artery and lead to disturbed flow within the stented artery. This disturbed flow can encompass flow separation and reattachment, stagnation and recirculation zones, long particle residence times, low and high shear stress (SS) within the blood flow, low and high WSS zones, oscillatory WSS, and high WSS gradient (WSSG) and angle gradient (WSSAG). Cellular components of the arterial wall are impelled to respond to this augmentation of the local hemodynamics in order to return the artery to a circular lumenal cross-section with smooth walls. Also, some of the changes in the local hemodynamics are not conducive to the natural healing of the arterial wall and instead hinder or adversely affect it, which consequently can lead to ISR.

The four interacting biological processes, instigated by these three effects of stent implantation, are thrombus formation, inflammation, neointimal hyperplasia (NIH) and re-endothelialisation. These biological processes, their interactions and the influences of the three instigators on each are described in the following sections, along with a review of the effects of stent design on these instigators and biological processes.
Thrombus Formation

Thrombus formation, in general, is the body's emergency response mechanism to structural injury and entails primary and secondary haemostasis. Primary haemostasis involves blood-borne platelets quickly adhering to form a plug at an injury site. Occurring in parallel with this is secondary haemostasis which involves the formation of fibrin fibres through the coagulation cascade, and these fibrin fibres bind the adhered platelets together at the injury site.

When structural injury is inflicted on an artery by stent implantation, platelets present in the bloodstream are activated by exposed collagen and plaque, and by proteins expressed by damaged ECs (e.g., fibronectin and von Willebrand factor (vWf)). Activated platelets are more sensitive to chemical signals and adhere to the collagen, plaque and proteins on the arterial wall, changing their cytoskeleton (cell scaffolding) to become more flexible and capable of spreading out over the injury site. Activated platelets also release platelet activating factor (PAF), adenosine diphosphate (ADP) and thromboxane A2 into the bloodstream which in turn activate more platelets and aid in the aggregation of platelets at an injury site. The coagulation cascade involves several coagulation factors present in the bloodstream and those released by adhered platelets and leukocytes, and VSMCs (e.g., tissue factor). Through the coagulation cascade prothrombin, present in the blood plasma, is converted to thrombin which both activates more platelets and causes soluble fibrinogen molecules in the blood plasma to convert into fibrin monomers. These fibrin monomers form fibrin fibres that bind the platelets that have aggregated together at the injury site, forming a thrombus.

In addition to this response to structural injury, thrombus formation is also initiated by the presence of a foreign body. Blood-soluble proteins adsorb onto the stent surface, forming a thin film which provides a provisional matrix that controls the subsequent biological processes of the foreign-body response. ${ }^{1}$ Different proteins (e.g., albumin, fibrinogen, fibronectin, vitronectin and y-globulin) adsorb onto the stent surface depending on the properties of the surface material. ${ }^{1}$ These adsorbed proteins produce different effects; fibrinogen for example is pro-thrombotic, promoting activation and adhesion of platelets, whereas albumin reduces platelet adhesion and aggregation. ${ }^{85}$ Fibrinogen is adsorbed preferentially over other proteins on many surfaces, especially polymers, ${ }^{85}$ and thus facilitates thrombus formation at a stent implantation site.

Thrombus formation has been found to be heavily flow dependent. The platelets, coagulation factors and 


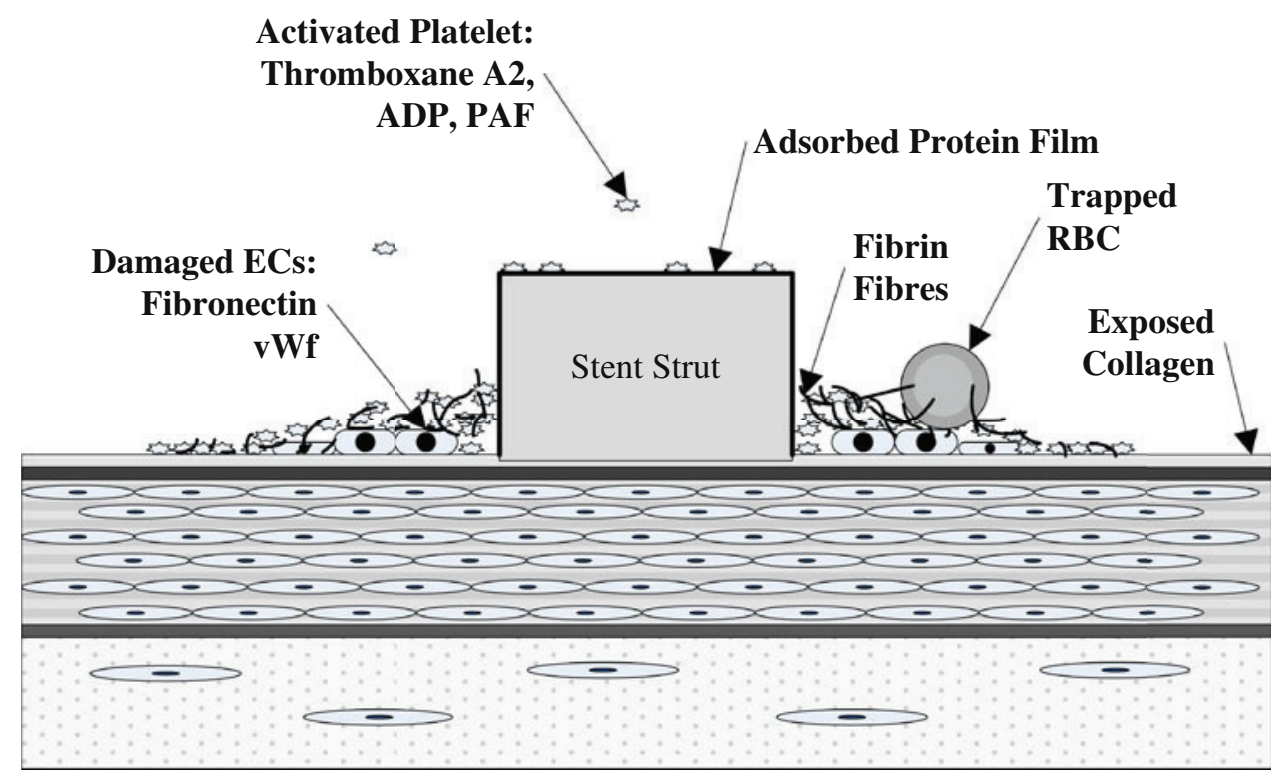

FIGURE 2. Diagram showing the cells, pro-thrombotic agents and proteins involved in thrombus formation at an injury site around a stent strut.

chemical substances involved in thrombus formation are predominantly blood-borne particles and as such their movements are dictated by the local hemodynamics. High particle residence times at the injury site facilitate increased platelet exposure times to thrombotic arterial wall components and activating chemical substances. This increased exposure time results in a greater probability of platelet activation ${ }^{2}$ with enhanced platelet activation being observed in low flow conditions. ${ }^{2}$ Increased platelet adhesion has been observed downstream of recirculation zones, where the main flow reattaches to the arterial wall, due to the convection of platelets towards the arterial wall. ${ }^{33,124}$ Red blood cells (RBCs) can also get trapped by fibrin monomers in the thrombus within recirculation zones or other low SS regions. Also, in regions of low WSS $\left(<10-12\right.$ dyne $/ \mathrm{cm}^{2}$ ) ECs respond by down-regulating the release of anti-thrombotic agents and up-regulating the expression of pro-coagulant and pro-thrombotic agents, thus also instigating thrombus formation. High SS within the blood flow can also activate platelets depending on the magnitude of the SS and the exposure time of platelets to this high SS. ${ }^{13}$ Figure 2 shows the cells (platelets, RBCs and ECs), pro-thrombotic agents and proteins involved in thrombus formation.

\section{Inflammation}

Inflammation involving leukocytes (e.g., lymphocytes, monocytes/macrophages, neutrophils, eosinophils and basophils) is the body's primary defence mechanism against infection. Leukocytes are attracted to an injury site in order to prevent the spread of the tissue damage and infection, and to aid in wound healing and tissue repair. ${ }^{94}$

Structural injury to the arterial wall by stent implantation triggers the expression of several cell adhesion molecules which mediate four steps, shown in Fig. 3, that each leukocyte undergoes in order to infiltrate an injury site. These four steps are the initial contact (tethering), leading to rolling and activation of the leukocyte, followed by firm adhesion and finally transmigration into the arterial wall. Tethering and rolling are mediated by cell adhesion molecules P-selectin (expressed by adhered platelets and damaged VSMCs) and E-selectin (expressed by damaged ECs) which interact with ligands expressed on the leukocyte surface. Firm adhesion is mediated by platelet glycoprotein (GP) Ib- $\beta$, vascular cell adhesion molecule 1 (VCAM-1) and intercellular adhesion molecule 1 (ICAM-1) expressed on the damaged wall, which interact with integrins expressed on the surface of the leukocytes, e.g., macrophage-1 antigen (MAC-1). The final step is driven by concentration gradients of chemokines (chemotactic cytokines) released by damaged ECs and VSMCs, and by the leukocytes already present at the injury site. Neutrophil infiltration of the injury site represents the initial acute phase of the inflammatory response and they are present up to, but not beyond, 30 days after BMS implantation. ${ }^{36}$ The chronic phase of the inflammatory response involving lymphocyte and monocyte infiltration of the injury site, extends from 3 days to beyond 6 months for BMSs. ${ }^{36}$ When monocytes migrate across the platelet/ fibrin thrombus to the site of initial injury, they differentiate into macrophages. These cells consume the 


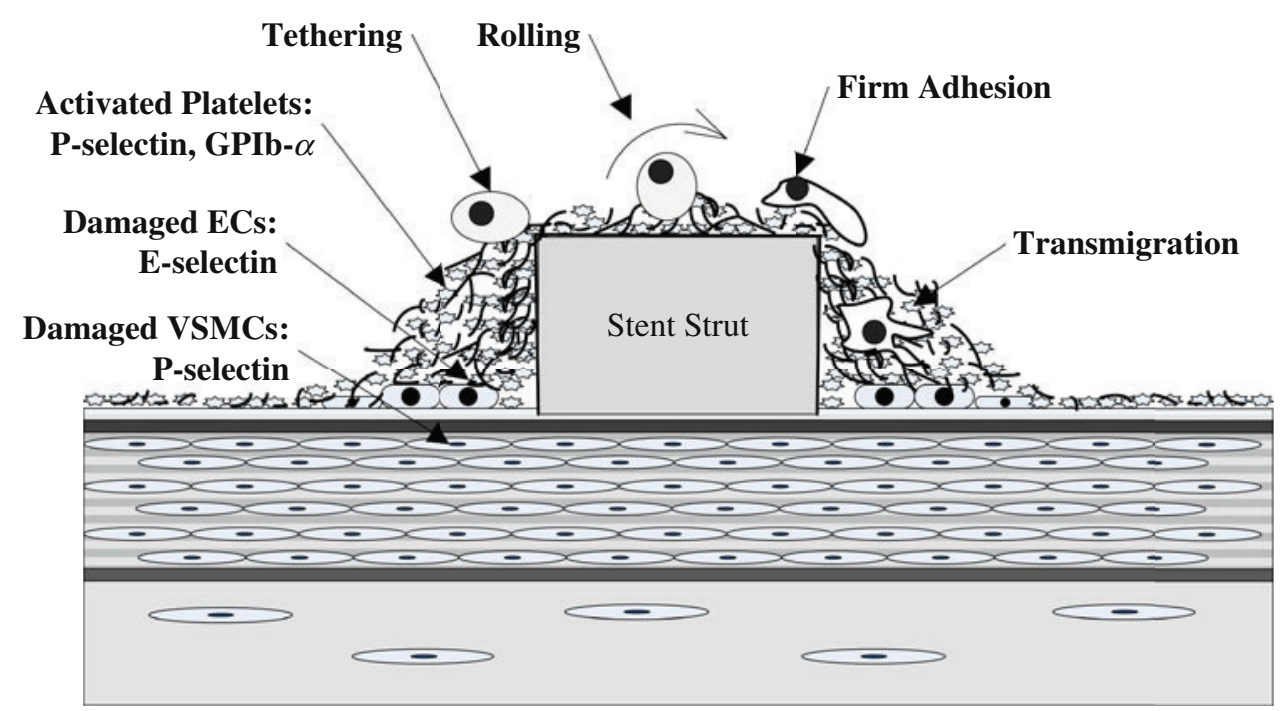

FIGURE 3. Diagram showing the four steps leukocytes undergo in order to infiltrate the injury site.

damaged cells around the injury site and also secrete interleukins which attract more leukocytes to the area.

The thin layer of proteins adsorbed onto the implanted stent surface not only mediates the adhesion of platelets, but also controls the inflammatory phase of the foreign-body response to the stent. The complement system, which consists of more than 20 plasma-based proteins, is a primary contributor to the innate immune system and is activated by the adsorbed protein layer. Activation of the complement system promotes the formation of enzymes and binding proteins which regulate the inflammatory response to a foreign body. Leukocytes, particularly neutrophils and monocytes, follow increased concentration gradients of chemo-attractant anaphylatoxins, such as C5a, which are fragments produced by activation of the complement system. Other products of complement activation, such as $\mathrm{C} 3 \mathrm{~b}$ and $\mathrm{iC} 3 \mathrm{~b}$, through a process called opsonisation mark foreign particles for phagocytic removal (ingestion) by leukocytes and subsequent proteolysis (digestion) by proteases (cellular enzymes). This is the case for any contaminants on the stent surface; however, in the case of a relatively large foreign body, such as a stent, which cannot be ingested, adhered neutrophils and monocytes undergo a frustrated phagocytosis whereby they release their array of potent oxygen metabolites and proteolytic enzymes. ${ }^{46}$ This can lead to an unresolved chronic inflammatory response exemplified by the increased fusion of macrophages into foreign body giant cells around an implanted stent. Platelets which adhere to the adsorbed protein layer on stent struts also release P-selectin to aid leukocyte adhesion and these adhered leukocytes can also encourage thrombus formation through elevated expression of tissue factor. ${ }^{35}$ Products of the complement system can interact with proteins involved in thrombus formation and thus, can also regulate each other. Metallic stent struts or the presence of a polymer coating on a stent can induce an allergic inflammatory reaction in some people, which is observed as eosinophil activation and presence at the implantation site. ${ }^{105}$

The local hemodynamics can also mediate the adhesion of leukocytes at an implantation site. With increased thrombus formation due to the hemodynamics in certain regions, e.g., re-attachment areas where flow is directed towards the arterial wall, there is a greater amount of cell adhesion molecules available to capture passing leukocytes. In addition to this, it has been found that local vascular hemodynamics can affect leukocyte ligand expression, ${ }^{40}$, shape ${ }^{23}$ and consequently interaction with other cells. ${ }^{142}$ Leukocyte-EC interaction is heavily influenced by the local hemodynamics which becomes more relevant as the endothelium reforms over the implantation site. For instance, leukocytes retract their pseudopodia (temporary projections from leukocytes used to adhere to a surface) when exposed to nitric oxide (NO), ${ }^{96}$ which is produced by functioning ECs in response to physiological WSS $\left(\approx 15\right.$ dyne $\left./ \mathrm{cm}^{2}\right) .{ }^{14}$ However, when ECs are exposed to low WSS $\left(<10-12\right.$ dyne $\left./ \mathrm{cm}^{2}\right)$ or disturbed flow they decrease their expression of antiinflammatory mediators (e.g., NO) and upregulate cell adhesion molecules (e.g., E-selectin, VCAM-1 and ICAM-1). Therefore, the establishment of normal physiological blood flow within a stented artery following the procedure is crucial to avoiding prolonged inflammation and consequently possible ISR. 


\section{Neointimal Hyperplasia}

NIH takes place up to 18 months post-implantation, results in a thickening of the intimal layer, and is the main cause of ISR. NIH involves the migration and proliferation of VSMCs originating in the media, and also differentiating from fibroblasts in the adventitia and bone-marrow-derived stem cells in the bloodstream. In addition, the VSMCs synthesise extracellular matrix (ECM). The degree of NIH is heavily influenced by the degree of thrombus formation and inflammation which takes place at an implantation site.

Damaged ECs and VSMCs, adhered leukocytes and platelets release cytokines (proteins used for intercellular communication) and mitogens (proteins which encourage a cell to commence the cell-division cycle) which encourage NIH at an injury site. The migration of the VSMCs is stimulated by cytokines [e.g., tumor necrosis factor (TNF) and interleukin-1 (IL-1)] released by macrophages and also by some of the mitogens (e.g., platelet-derived growth factor (PDGF)). PDGF is capable of stimulating migration at a much lower concentration level than that needed for cell division ${ }^{48}$ and therefore, migration is an earlier response than proliferation. In order for migration to occur enzymes [e.g., matrix metalloproteinase (MMP)-9] released by adhered leukocytes and VSMCs help in the dissolution of the IEL and the existing ECM. This dissolution, along with the disruption to the ECM caused by stent implantation, allows the medial VSMCs and myofibroblasts (activated fibroblasts) to migrate through to the neointimal region of the arterial wall. The proliferation of VSMCs is instigated by mitogens [e.g., serotonin, thromboxane $\mathrm{A}_{2}$, PDGF and basic fibroblast growth factor (bFGF)] which are released by damaged ECs and VSMCs, adhered leukocytes and platelets. This proliferation produces a greater amount of neointimal cells than does migration. In addition to VSMC migration and proliferation, inflammatory and hematopoietic cytokines [e.g., granulocyte colonystimulating factor (G-CSF)] produced by ECs and leukocytes at the injury site mobilise stem cells from the bone marrow to enter the bloodstream. ${ }^{68,69}$ These stem cells can differentiate into smooth muscle progenitor cells (SPCs), which adhere to fibronectin and differentiate into VSMC-like cells in the presence of PDGF-BB (a PDGF isoform) at the injury site. ${ }^{53,131}$ The stretching of the original VSMCs in the arterial wall stimulates them to synthesise collagen, a component of ECM, which may serve to alleviate the additional stress caused by stent implantation, but also increases the overall wall volume. ${ }^{84}$ This, along with the synthesis of ECM by neointimal VSMCs can contribute up to $80 \%$ of the resultant wall thickening. ${ }^{44}$
Leukocytes and platelets attracted to a foreign body can also release cytokines and mitogens which encourage NIH. Macrophages activated by biomedical polymers in vitro have been shown to stimulate fibroblast activity. ${ }^{1}$ In addition to this, macrophages and foreign-body giant cells on a biomaterial surface modulate ECM fibrosis. This results in the formation of a fibrous capsule, mainly comprised of collagen fibres and leukocytes, which isolates the stent from the surrounding tissue and blood. ${ }^{1}$

NIH can also be induced and influenced by local hemodynamics within the stented arterial region. Where local hemodynamics cause increased thrombus formation and inflammation, due to the release of mitogens by adhered leukocytes and platelets, this subsequently induces increased NIH. In regions where the endothelium has been denuded and the IEL damaged by stent implantation, underlining VSMCs may be exposed and affected by the local hemodynamics. Human VSMCs exposed to physiological or high WSS (14 and 28 dyne $/ \mathrm{cm}^{2}$ respectively) for $24 \mathrm{~h}$ show an increase in transforming growth factor (TGF)-1 expression which inhibits their proliferation, in comparison with a static control. ${ }^{148}$ High WSS ( $>15$ dyne $/ \mathrm{cm}^{2}$ ) also stimulates the release of stored mitogens (PDGF and bFGF) within VSMCs into the bloodstream while low WSS increases VSMC susceptibility to these mitogens. ${ }^{135}$ Thus, in a stented artery where there is variability between high and low WSS across the stent and arterial wall, increased proliferation would occur in low WSS zones. ${ }^{101}$ In addition, pulsatile turbulent WSS has also been found to stimulate VSMC proliferation, ${ }^{129}$ and murine VSMCs exposed to steady laminar WSS of 15 dyne $/ \mathrm{cm}^{2}$ have been found to transdifferentiate into ECs. ${ }^{152}$ Within the arterial wall, VSMCs and myofibroblasts are exposed to transmural interstitial shear stress which can be increased by endothelium denudation, activating these cells and promoting their migration into the intima or wound site. ${ }^{127}$ ECs present in the stented region downregulate anti-proliferative gene expression and upregulate the release of VSMC growth factors in response to low WSS. ${ }^{14}$ The oxygen flux from the blood into the arterial wall, which is also heavily flow dependent, has also been found to influence VSMC behaviour. NIH has been found to be reduced in rabbits treated with supplemental oxygen, ${ }^{83}$ and areas of low WSS where the oxygen flux into the arterial wall is low are hypothesised to experience increased NIH. ${ }^{144}$

\section{Re-Endothelialisation}

The endothelium fulfils several important physiological functions which include acting as a selective 
permeability barrier, participation in cardiovascular homeostasis and inflammatory responses, regulation of cellular growth and proliferation within the arterial wall, angiogenesis and tumour metastasis. ${ }^{121}$ Considering its importance, once denudation by stent implantation has occurred, its reinstatement, i.e., re-endothelialisation, is critical in order for the artery to return to its normal functioning behaviour.

Damaged ECs, adhered platelets, VSMCs and macrophages present at the injury site release mitogens capable of instigating re-endothelialisation. These mitogens include vascular endothelial growth factor (VEGF), PDGF and bFGF and induce the ECs remaining around the stent struts and outside the stented area to migrate and proliferate into the denuded section. In addition, increased levels of VEGF circulating in the bloodstream induce precursors of endothelial cell colony forming units (EC-CFUs) (angiogenic monocytes and lymphocytes) and endothelial progenitor cells (EPCs) derived from bone marrow stem cells, to mobilise, enter the bloodstream and home in on the injury site. It has been hypothesised that EC-CFUs precursors arrive earlier than EPCs to provide rapid coverage of the injury site and secret angiogenic factors (e.g., VEGF and G-CSF) which encourage EPC homing and proliferation. ${ }^{106}$ EPCs attach to proteins and adhesion molecules on the arterial wall and subsequently differentiate into mature ECs.

ECs or EPCs will not adhere directly to, or proliferate over, a normal stent surface ${ }^{25}$ and as such re-endothelialisation over the stent struts cannot occur without an adsorbed protein layer and adhesion molecules expressed by cells adhered to the surface. Some stent designs endeavour to promote re-endothelialisation by applying coatings to the stent surface. ${ }^{5,25,128}$ The surface texture of a stent also influences re-endothelialisation and thus some new stents are exploring different surface modifications which may aid re-endothelialisation. ${ }^{6}$ In addition to this the surface chemical composition also affects re-endothelialisation, e.g., endothelial migration onto stainless steel via interaction with adsorbed fibrinogen is significantly greater than that observed onto gold surfaces. This could be due to the surface charge, hydrophobicity, or chemical composition of the surface material. ${ }^{133}$

Local hemodynamics at a stent implantation site also have an effect on the initial and continued adherence of ECs and EPCs. Large WSS oscillations over positive and negative values, i.e., $1 \mathrm{~Hz}$ reversing sinusoidal WSS of mean $20 \mathrm{dyne} / \mathrm{cm}^{2}$ with an amplitude of 40 dyne $/ \mathrm{cm}^{2}$, has been found to cause the detachment of cultured bovine aortic ECs, ${ }^{58}$ which would delay re-endothelialisation. ECs have been shown to migrate downstream of an area where the
WSSG is above 30 dyne $/ \mathrm{cm}^{3} \cdot{ }^{24,145}$ The migration of ECs into denuded areas from adjacent areas with an intact endothelium has been shown to be increased when exposed to undisturbed laminar flow as opposed to disturbed laminar flow or static flow. ${ }^{66}$ Re-endothelialisation of the stent surface has also been found to be WSS dependent, with low WSS regions experiencing delayed re-endothelialisation and high WSS encouraging EC migration onto stent surfaces. ${ }^{132}$ In addition to this, as the healing process progresses and the endothelium layer reforms, ECs can sense and are responsive to WSS conditions. In physiological flow conditions ECs align themselves in the flow direction and are in an atheroprotective state, releasing anticoagulants, antioxidants and vasodilators such as NO. When ECs are in regions of low WSS or high WSSG they switch to an atherogenic state in which they adopt a cobblestone shape in a more random arrangement, shown in Fig. 4, no longer aligned with the flow and presenting gaps in the endothelial layer, thus encouraging cellular and lipid infiltration. ${ }^{110,118-120}$ In this form they also up-regulate inflammatory mediators, adhesion molecules, procoagulant and pro-thrombotic agents, and VSMC growth factors, all of which can lead to increased NIH and result in ISR. ${ }^{87}$

\section{The Influence of Stent Design on ISR}

There are many different stents available on the market with varying strut configurations, thicknesses, materials, and deployment mechanisms, and in the case of DESs different coatings, drug types, doses and drug release kinetics. These varying designs produce different degrees of structural injury, foreign-body reactions and hemodynamic flow field alterations, which in turn affect the biological processes taking place within the stented artery and the resultant ISR rates. A study by Kastrati et $a l^{74}$ of 3,370 patients (4,229 stented lesions) who underwent angioplasty with stenting using different BMS types concluded that following vessel size, stent design was the second strongest factor in determining the occurrence of ISR.

The structural injury caused by stent implantation to the arterial wall is assumed to be proportional to the stress induced within the wall, which is dependent, in part, upon the stent design. Self-expanding stents have been found to cause less injury to the endothelium than balloon-expandable stents, because only the stent struts, in contrast with both the struts and an expanded balloon, are in contact with the arterial wall. ${ }^{54}$ The injury caused by the balloon depends on the inflation pressure, stent geometry and distance between struts. ${ }^{117}$ Stent foreshortening upon expansion, elastic recoil, ${ }^{32}$ and deformations of the stent under flexion, ${ }^{155}$ 

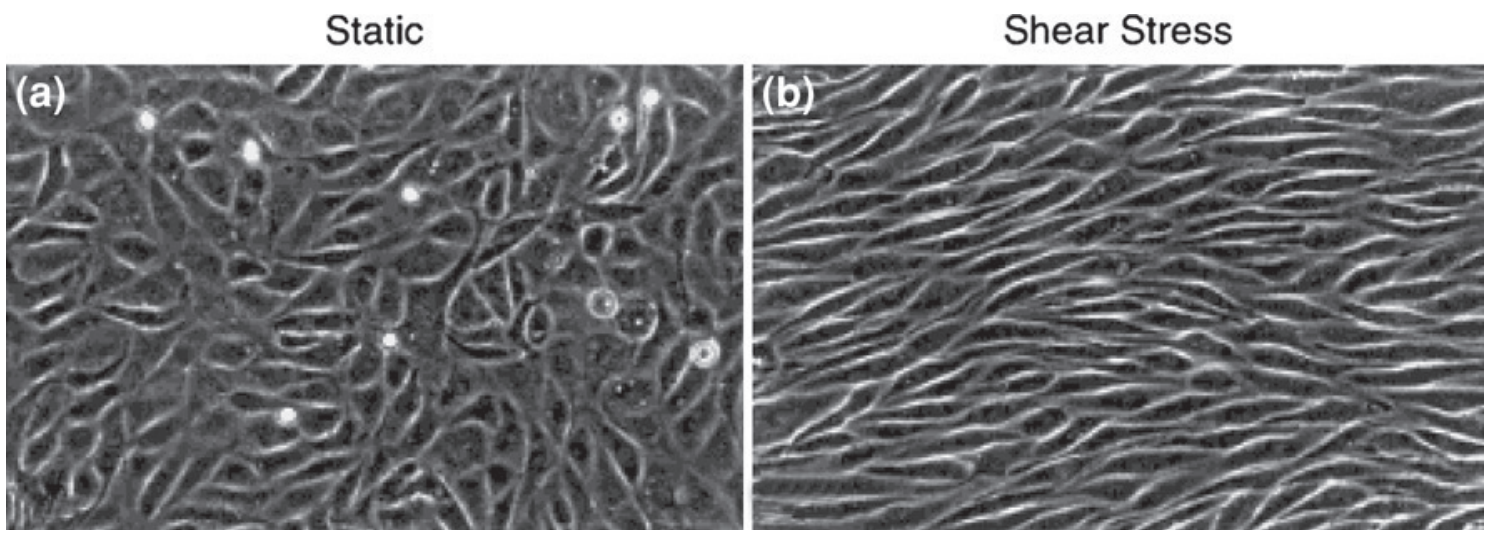

FIGURE 4. Phase-contrast monographs of confluent bovine aortic endothelial monolayers show a distinct difference between ECs under static flow conditions (a) and those exposed to physiological WSS for $24 \mathrm{~h}$ (b). Reproduced and adapted with permission from the Journal of Cell Science. ${ }^{88}$

603 have been studied using finite element analysis and are 604 hypothesised to affect the degree of injury inflicted 605 upon the arterial wall. High stresses within the arterial 606 wall can cause increased damage, and in the case of 607 medial injury and lipid core penetration by stent struts 608 there is a propensity for increased inflammation. ${ }^{36}$ By 609 reducing the number of strut-strut intersections by one 610 third, disruption of the IEL and the media layer were 611 reduced by nearly one half in a study of steel stents 612 deployed in denuded rabbit iliac arteries. ${ }^{115}$ Several 613 clinical studies have linked the degree of arterial wall 614 prolapse between stent struts with the occurrence of 615 ISR. ${ }^{61,70,111}$ The amount of prolapse between stent 616 struts is also dependent on the strut spacing. Following 617 implantation, a stent must also be able to withstand 618 additional stresses placed upon it from vessel defor619 mation. In the case of coronary arteries the beating of 620 the heart causes slight movements and deformations of 621 the arteries. ${ }^{26-28}$ Also, in peripheral arteries, such as 622 the femoral, popliteal and tibial arteries, deformation 623 is caused by the flexion of the hip, knee or ankle, which 624 in some cases can cause fracture of an implanted stent 625 possibly resulting in renewed injury to the arterial wall 626 and ISR. ${ }^{123}$ Therefore, not only does the stent design 627 have an effect on the structural injury inflicted on the 628 arterial wall initially, but the properties of the stent 629 material and its ability to withstand cyclic loading of 630 the heart beating or a limb moving can also affect the 631 probability of ISR occurring during the lifetime of a 632 stent.

633 The stent material also has implications on each 634 biological process in the response to a foreign body. 635 Stainless steel, used in most BMSs, is found to oxidise 636 in the body causing varying degrees of cell toxicity. ${ }^{156}$ 637 First-generation DES permanent polymer coatings 638 were found to cause delayed healing, impaired stent 639 strut endothelialisation, and hypersensitivity reactions, 640 which can culminate in stent thrombosis in some cases. $^{42,72,73,103,149,151}$ In a study of different DESs implanted in rabbits by Joner et al. ${ }^{73}$ it was found that struts lacking endothelial coverage at 14 days showed focal aggregates of platelets and inflammatory cells, including foreign body giant cells. Therefore, in the absence of complete endothelialisation of polymeric strut surfaces increased inflammation and thrombus formation may result. New DES coatings such as phosphorycholine and the co-polymer poly(vinylidene fluoride-co-hexafluoropropylene) mimic the phospholipids on the outer surfaces of red blood cells. ${ }^{92}$ This improves the biocompatibility of the DES by masking its foreign nature. As a result of the observed detrimental effects of permanent polymers implanted in the body, biodegradable polymer coatings and completely polymer free stents are also being developed. ${ }^{43}$

The resultant local hemodynamics created within the stented lumen are also partially dependent on the stent design. Thrombus formation, as mentioned previously, is heavily flow dependent with highest platelet deposition occurring where flow is directed towards the arterial wall. ${ }^{33}$ Monocyte adhesion rates were found to be affected by not only the local WSS, but also the radial component of velocity and the dynamics of the recirculation region and flow reattachment. ${ }^{112}$ Flow separation away from the arterial wall and recirculation zones occur both upstream and downstream of rectangular cross-sectional stent struts. Platelets within these zones experience long particle residence times in proximity to activating substances, which increases their probability of activation. With thinner and more streamlined stent struts, the recirculation zones, and also consequently, the particle residence times can be reduced. ${ }^{71}$ WSS, WSSG and WSSAG within an idealised stented artery can be predicted using computational fluid dynamics (CFD) and different stent designs have been shown to produce significantly different distributions of each. ${ }^{81,82,101}$ The angle that stent struts 
make with the primary direction of blood flow has been shown to strongly influence the amount of intrastrut area of the lumenal wall exposed to low WSS. ${ }^{82}$ Stents with a greater final diameter than the implanted artery not only cause increased damage within the arterial wall, but also increase the cross-sectional area of the stented artery, reducing the blood flow velocity and as a result reduce the WSS within that region. Alternatively, stent undersizing can result in stent strut malapposition to the arterial wall, thus increasing the resistance to flow and decreasing the WSS. ${ }^{16}$

\section{FLOW-AUGMENTATION STENT DEVICES}

\section{Introduction}

CFD analyses, in vivo and in vitro studies have been used to assess the effects of stent implantation on the local hemodynamics. ${ }^{33,34,57,80,81,101}$ These studies concentrate on existing stents which fulfil the basic role as a scaffold to keep an artery open. Novel complementary devices and stent designs have been, and are currently being, developed which not only re-establish blood-flow in an obstructed artery but establish hemodynamics which inhibit ISR.

\section{ARED Flow Divider}

The Anti-Restenotic Diffuser (ARED) flow divider, as shown in Fig. 5, was developed on the premise that increasing the WSS in a stented artery decreases the risk of developing excessive IH, resulting in ISR. The device was patented by Dr Nikolaos Stergiopulos of the Ecole Polytechnique Federale de Lausanne (EPFL) in Switzerland in 2000 (European Patent EP0989830). The concept behind the ARED flow divider is that, upon insertion within the stented region, self-expanding appendages which press against the arterial wall hold a central solid cylinder along the artery's central axis. The overall cross sectional area of the artery is thus reduced, as shown in Fig. 6, thereby increasing

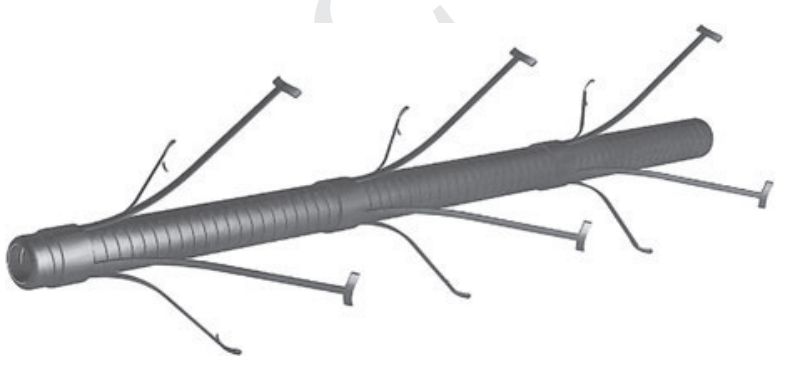

FIGURE 5. ARED flow divider for insertion in a stented artery. It is held in place by the self-expanding appendages radiating out from the central cylinder which press against the arterial wall. $^{8}$ the blood-flow velocity close to the wall and, in turn, the WSS. This, in theory, reduces the extent of low WSS regions and hence the amount of NIH in the stented region.

Wentzel et al. ${ }^{154}$ investigated the relationship between WSS, predicted by CFD analysis of reconstructed geometries approximating the lumen after stenting, and the observed neointimal thickening in 14 patients at 6 month follow-up after coronary Wallstent implantation. An inverse relationship between in-stent neointimal thickening and WSS distribution in vivo was found. Wentzel et al. ${ }^{153}$ stated that in line with this work Endoart, founded by Dr Nikolaos Stergiopulos, developed the ARED flow divider. Carlier et al. ${ }^{8}$ published results which demonstrated the proof of concept of the ARED flow divider through the analysis of histological arterial cross sections obtained from nine New Zealand White rabbits implanted with just a MultiLink stent in one of the external iliac arteries (control segment), and implanted with both a MultiLink stent along with an ARED flow divider in another. CFD was used to estimate the alteration of WSS in the stented artery due to the presence of the ARED flow divider using two idealised tubes: one with a centrally-located cylinder (approximating the segment with the ARED flow divider) and one without (approximating control segment). The increase in WSS (from 3.8 to 8.2 dyne $/ \mathrm{cm}^{2}$ as predicted by the idealised CFD analysis), caused by the presence of the ARED flow divider in comparison to the control segment, resulted in local reductions in injury and inflammation score, and NIH following stent implantation. Based on this observation, Carlier et al. ${ }^{8}$ concluded that this study supports the hypothesis that increasing the WSS within a stented region can lead to decreased accumulation of macrophages, preventing IEL dissolution and subsequent VSMC migration within that region. Histological cross sections obtained in the study are shown in Fig. 7.

Sanmartin et al. assessed the influence of WSS on ISR using a combination of angiography and intravascular ultrasound of the right coronary artery of seven patients following stent implantation, along with the results from CFD analyses of reconstructed geometries of the implanted arteries. In this study, an inverse relationship was found between WSS and NIH; however, it was noted that the conclusions drawn from the study by Carlier et al. ${ }^{122}$ should not be extrapolated directly to humans, given that flow conditions, vascular geometry and response to lesions are very different in humans compared with rabbits.

The ARED flow divider was never implanted in humans ${ }^{77}$; however, these studies demonstrate that local WSS distribution could influence NIH and there was a potential application of this fact in the design of new vascular devices. 
(a)

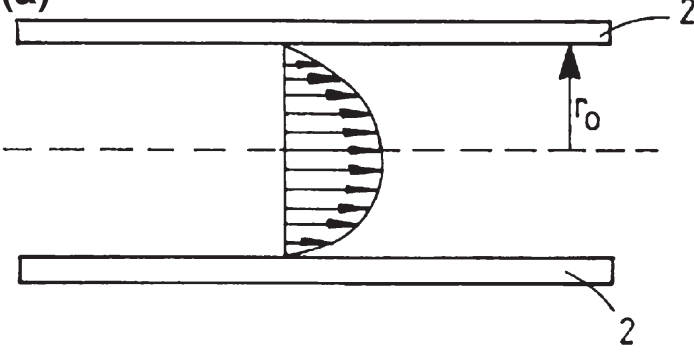

(b)

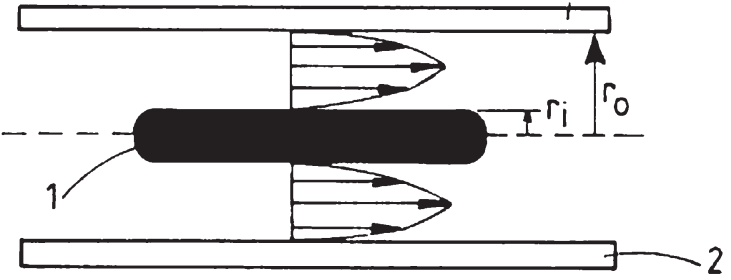

FIGURE 6. (a) and (b) Diagrams taken from European Patent EP0989830 (B1) showing the axial velocity distribution across an idealised artery before (a) and after implantation (b) of an ARED flow divider. The central cylinder is marked 1 above in (b) and the arterial wall is marked 2 in both diagrams. The axial velocity distribution is a function of the radius, $r$, with $r_{i}$ representing the outer radius of the cylinder and $r_{\mathrm{o}}$ representing the inner radius of the artery. ${ }^{134}$

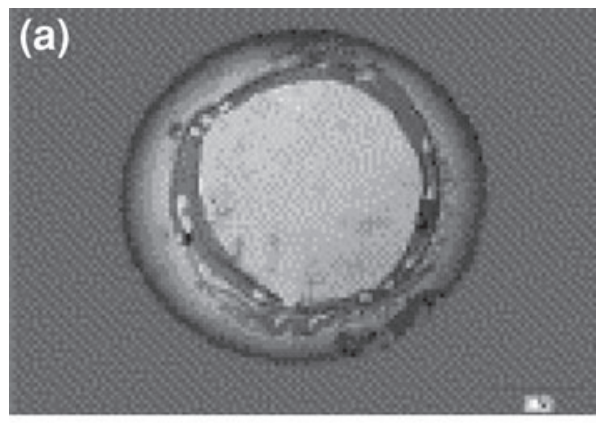

Stent with fow divider

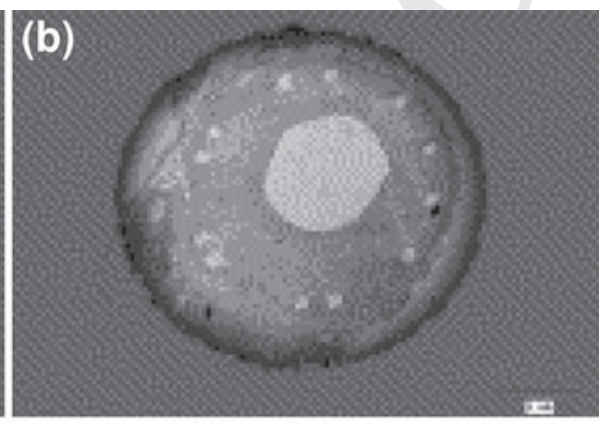

Stent without fow divider

FIGURE 7. Histological cross-sections taken from a stented arterial segment with (a) and without the flow divider (b). Reduced NIH is clearly observed in the region with the flow divider present. ${ }^{8}$

\section{Helical Flow Devices}

The local hemodynamics have a significant influence on the cellular activity within an arterial wall. Atherosclerosis has been found to preferentially develop in areas of disturbed flow and regions of low WSS. ${ }^{12,14,17,79,136}$ Natural blood flow in the arterial system has been found to be helical in nature. The beneficial/detrimental implications of helical flow in the cardiovascular system are open to conjecture. ${ }^{47}$ However, two novel stent designs are being developed that endeavour to elicit helical flow and take advantage of its beneficial characteristics in terms of inhibiting atherosclerotic lesion development and ISR.

\section{Helical Flow}

Experiments conducted by Caro $^{9}$ on the dispersion of indicator flowing in simplified models of the circulatory system showed that large secondary motions were induced by bends in the models. It was postulated that these secondary motions had particular physiological importance in circulation, listing possible advantages as being the prevention of stagnation zones and flow separation at the arterial walls. Inspired by observations of spiral folds on the inner endoluminal surface of arteries using fibre-optic angioscopy by
Stonebridge and Brophy, ${ }^{139}$ postulated by Caro et al. ${ }^{11}$ as being helical distributions of lesions due to low WSS zones, Stonebridge et al. went on to show that blood flows in the right common and distal superficial femoral and the left common femoral arteries with a secondary rotational motion which produces an overall spiral (helical) flow. This was detected using Doppler ultrasound with the probe aligned perpendicular to the axial flow, as shown in Fig. 8 along with a sample ultrasound image. ${ }^{141}$

The terms spiral flow and helical flow are used interchangeably in the literature, but for the purpose of this paper, helical flow is the term used. The helical flow in arteries is induced by their non-planar curvature and the heart itself. It has been proposed that the secondary motion, i.e., the rotational motion, of the blood flow is induced by the twisting of the left ventricle during contraction, ${ }^{91}$ and then accentuated upon entering the aortic arch. ${ }^{39,75}$ This twisting is, in part, due to the structure of the ventricular myocardial band of the heart which has been found by Torrent-Guasp to be spatially orientated in the form of a helix. ${ }^{147}$ Brecher $^{7}$ also observed that there existed a continuous negative pressure within the ventricle which Marinelli ${ }^{90}$ cited as evidence of a perpetual vortex within the ventricle, which provides the ventricular suction during 

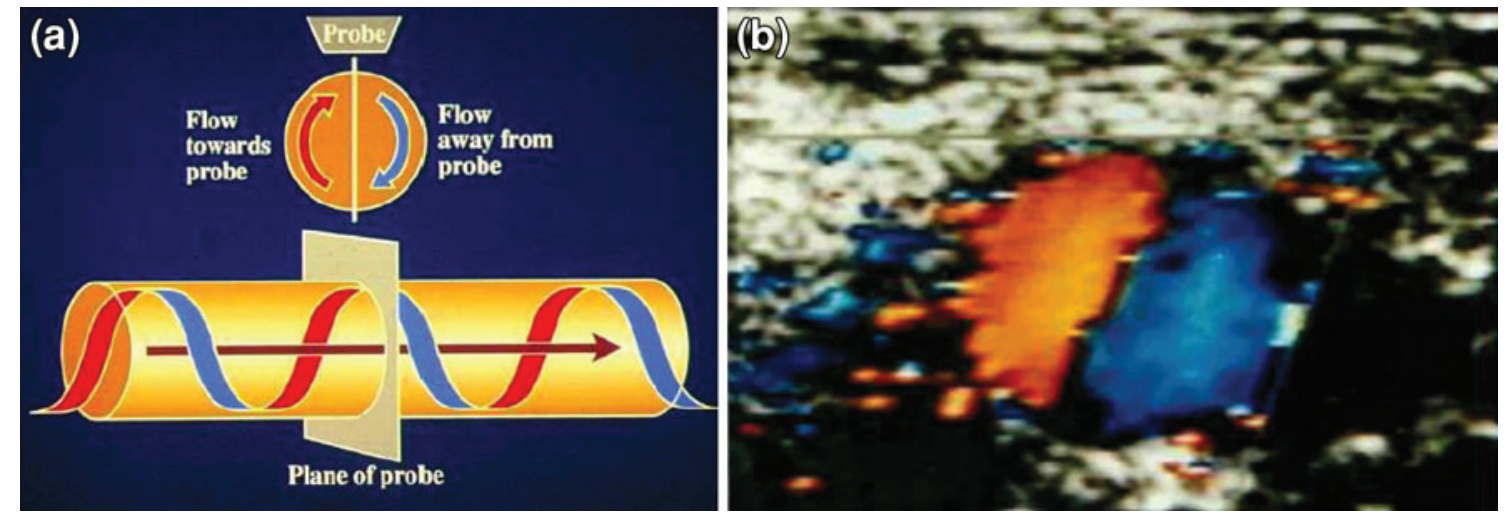

FIGURE 8. (a) The Doppler ultrasound set up used in the experiment described by Stonebridge et al. ${ }^{141}$ (b) This sample image clearly shows the characteristic red/blue split signifying helical flow as observed in vivo. ${ }^{138}$ Reproduced with permission from Vascular Flow Technologies.

the diastolic period, and possibly incites the initial helical flow. Helical flow had been observed before in the human aorta by Segadel and Matre ${ }^{125}$ and again by Kilner and Guang ${ }^{75}$ using magnetic resonance imaging (MRI), and by Frazin et al. ${ }^{39}$ in canine thoracic and abdominal aortae using Doppler ultrasound, but the studies by Stonebridge et al. were the first to show that the helical flow was maintained in the peripheral arteries also. Suo ${ }^{143}$ concluded, following MRI and CFD analysis, that helical flow in the aorta could only be produced by including the specific aortic motion caused by the beating heart. Caro et al. ${ }^{11}$ published observations from MRI data of flow through healthy human arteries with non-planar curvature and branching which showed how these features appeared to significantly affect the hemodynamics, including WSS.

Many of the beneficial effects of helical flow in the arteries were originally only postulations by researchers in the area; however, there is growing evidence which support these postulations. Stonebridge et al. ${ }^{141}$ discuss how there are theoretical advantages to helical flow, including rotationally-induced stability, reduced turbulence, and a beneficial effect on mechanisms of endothelial damage. A paper by Caro et al. ${ }^{11}$ it was highlighted that greater mixing and more uniform WSS was expected in the cardiovascular system which was found to be commonly non-planar. Doorly et $a .^{29}$ found through CFD analysis that a simple modification to the geometry of an end-to-side anastomosis, where the graft is rendered approximately helical, produced a profound effect on the flow, enhancing the swirling motion of the flow downstream. Zabielski and Mestel ${ }^{157}$ concluded from a CFD analysis into helical flow around arterial bends that the non-planar curvature limits the severity of flow separation at the inner bend and reduces variation of the WSS. This was confirmed in a CFD analysis by Papaharilaou et al. ${ }^{108}$ of planar and non-planar end-to-side anastomoses where it was found that the introduction of an out-of-plane curvature produced a significant change in the spatial distribution of WSS and a $10 \%$ reduction in the time-averaged peak WSS magnitude. The spatial extent of the elevated oscillatory WSS regions was reduced in the non-planar model in comparison with the planar model and given that $\mathrm{Ku}$ et $\mathrm{al}^{79}$ found a correlation between elevated oscillatory WSS and NIH there are effectively less areas exposed to unfavourable, in terms of disease progression or ISR, flow conditions in the non-planar geometry. In a numerical study of vortical flow identification and flow transport in arterial graft geometries, Doorly et al. ${ }^{30}$ found that significant greater particle mixing was prevalent in the non-planar geometry compared with the planar geometry, with continual transport of particles away from the wall, thus lessening near-wall particle residence times. Stonebridge et al. ${ }^{140}$ compared helical and non-helical flow patterns through stenoses using MRI in vitro and CFD modelling. In this study it was found that nearwall turbulence energy was up to $700 \%$ less with helical flow than non-helical flow beyond the stenosis, with turbulence being associated with substantial WSS fluctuations in both space and time. ${ }^{89}$ The degree of helical flow has been found by Houston et al. ${ }^{63}$ to be reduced in atherosclerotic arteries, although a direct relationship between atherosclerotic lesions and the absence of helical flow has not been proven, and within these arteries the turbulent nature of the resulting flow encourages further development of the disease. A study by Morbiducci et $a l{ }^{98}$ indicated that helical flow dampened WSS temporal gradients in aortocoronary bypass grafts. Morbiducci et al. ${ }^{100}$ also conducted an in vivo investigation into the helical flow patterns in the aortic region of five healthy humans using 4D phasecontrast MRI, and CFD analyses of the reconstructed aortic geometries. It was found that helical-blood-flow dynamics is common to healthy individuals, and that 
helical flow might be caused by natural optimisation of fluid transport processes in the cardiovascular system, aimed at obtaining efficient perfusion of blood and nutrients therein to the organs and tissue. In predicting these transport processes, and also those involved in atherogenesis, a paper by Chiastra et al. ${ }^{18}$ highlighted that flow properties such as velocity, helicity and vorticity are primarily responsible, and that researchers should consider these bulk flow properties in addition to the WSS variables. Liu et al. ${ }^{86}$ conducted a CFD study of the transport of low density lipoprotein (LDL) in four models of human aortae and found that the helical flow induced in the aortic arch had a beneficial effect on LDL concentration at the arterial wall. Helical flow has also been shown to be instrumental in moderating shear-induced activation of platelets, which is a problem for some cardiovascular implants. ${ }^{93,99,158}$ Massai et al. ${ }^{93}$ found through CFD simulations of a reconstructed model of a left carotid bifurcation that an inverse relationship existed between the helical flow index (variable for measuring the helical structure of the flow) and the probability of shear-induced activation of platelets.

An analysis by Paul and Larman ${ }^{109}$ using CFD of helical flow downstream of a $75 \%$ stenosis found that turbulent kinetic energy was reduced post stenosis. The helical motion provides rotational stability to the flow, reducing flow disturbance and turbulence, which is a beneficial effect. Conversely, as noted by Paul and Larman, ${ }^{109}$ helical flow also produced oscillating WSS in the post-stenosis model, which is considered a detrimental effect possibly causing damage to the endothelium. In addition to this, other researchers have speculated on whether the effects of helical flow are entirely beneficial. Frazin et $a .^{38}$ considered that although the rotational element of the flow may be important physiologically for organ perfusion, pathologically, there may be a relation between the shear forces induced by helical flow and plaque deposition. A paper by Texon ${ }^{146}$ showed that "serpentine flow" in relatively straight vessels may also produce zones of diminished lateral pressure and atherosclerosis. A CFD study of helical grafts by Zheng et al. ${ }^{159}$ found that along with the benefits of increased WSS and swirling flow, there was also an enlarged pressure drop and low velocity concentrated in one area in a helical graft model which could lead to increased NIH or thrombosis. Pressure drop was found to be proportional to the helicity of an inlet flow into an idealised stented artery in a CFD study by Chen et al. ${ }^{15} \mathrm{CFD}$ simulations conducted in this study showed pressure drops for the stent with swirling flow to be 164, 167 and $173 \mathrm{~Pa}$ for inlet helicities of $3.5,6.4$ and $14.5 \mathrm{~m} / \mathrm{s}^{2}$, respectively, whereas for the stent with normal inlet flow the pressure drop was $163 \mathrm{~Pa}$. Beneficial effects of helical flow also noted in this paper were that the average lengths of the recirculation zones between the stent struts and oscillatory shear index (OSI), a measure of the change in direction and magnitude of the WSS vectors during the cardiac cycle, were reduced with increasing helicity of the inlet flow, which enhanced the average WSS in comparison with normal flow. ${ }^{15}$

Considering the correlation between adverse flow conditions and increased $\mathrm{NIH}^{3,45,55,59,76,107}$ and the effects of the local hemodynamics on the other biological processes leading to ISR, discussed in "In-Stent Resteno" section, there are two particular stents which are embracing the beneficial effects of helical flow, i.e., increasing particle mixing, reducing areas of disturbed flow and providing a more uniform WSS, and endeavour to restore this natural blood flow pattern in a stented artery.

\section{BioMimics 3D Helical Stent}

The BioMimics 3D helical stent is being developed by Veryan Medical Ltd which has its head office in Horsham, West Sussex, UK and research and development based in Galway, Ireland. This stent appears to have evolved from a helical bypass graft, marketed as SwirlGraft, which incorporated Small Amplitude Helical Technology (SMAHT), developed at Imperial College London. The theory behind this technology is that a normal planar bend induces two equal but opposite Dean vortices within the flow, whereas in a non-planar bend, as found in SMAHT, one of the vortices begins to dominate the other as the flow progresses through the bend, producing helical flow. Caro et al. ${ }^{10}$ compared SwirlGraft devices with conventional expanded polytetrafluorethylene (ePTFE) arteriovenous shunts in two pigs. Even though the experiment was limited by the number of pigs employed, the results of this study were still positive with consistently less thrombus formation and NIH in SwirlGraft devices compared with the conventional devices. Interestingly, when the porcine arterial sections were analysed, two seemingly helical ribbons of NIH were found which seemed to match with the predicted areas of low WSS in a CFD model of SwirlGraft. A clinical trial was carried out by Huijbregts et al. ${ }^{67}$ in which 20 patients requiring vascular access grafts were implanted with SwirlGraft. It was found that the graft was prone to thrombosis, possibly due to the loss of the helical geometry of the graft upon implantation. It was concluded by Huijbregts et al. ${ }^{67}$ that with modifications to implantation techniques and the SwirlGraft design that the product might advance to a randomised controlled trial. 


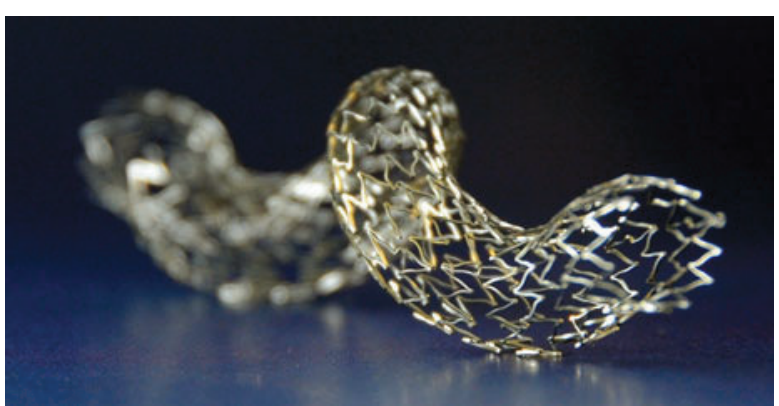

FIGURE 9. BioMimics 3D helical stent. Reproduced with permission from Veryan Medical Ltd.

1006

1007

1008

1009

1010

1011

1012

1013

1014

1015

1016

1017

1018

1019

1020

1021

1022

1023

1024

1025

1026

1027

1028

1029

1030

1031

1032

1033

1034

1035

1036

1037

1038

1039

1040

1041

1042

1043

1044

1045

1046
Veryan Medical has taken this same SMAHT technology and applied it to peripheral stent design in the form of the BioMimics 3D helical stent, shown in Fig. 9, possibly with the aim of entering into the broader stent market once the technology has been proven. In addition to the helical flow benefits, the stent also includes design features such as tapered radial stiffness and collinear stent ends which, in theory, help in providing a more gradual change in the wall stress and lumenal area between the unstented and stented portion of the artery, as opposed to a dramatic change which could form a stagnation zone in the flow, encouraging thrombus and neointimal formation. For peripheral stent implantation, in the femoral artery particularly, as the leg bends the stent must be flexible enough to allow movement and longitudinal slackening of the artery without stent fracture or the infliction of damage on the arterial wall. The BioMimics 3D helical stent has been assessed in this regard through a human cadaver study as stated on the company website (http://www.veryanmed.com/). In this study the BioMimics 3D stent and control straight stents were implanted in the lower and mid superficial femoral artery and the upper popliteal fossa of three cadavers and the knee joint was flexed over a range of angles. It was observed that the BioMimics 3D helical stent could increase its helicity and thus take up the slack in the artery upon flexion of the knee, while also avoiding permanent deformation, unlike the straight stents. This ability is deemed a valuable characteristic which could prolong the life of a peripheral stent by absorbing stresses which ordinarily could cause fracture.

As mentioned earlier, studies by Lee et al. ${ }^{83}$ into the effects of supplemental oxygen on NIH and by Tarbell ${ }^{144}$ into mass transport of molecules, e.g., oxygen, into arterial walls and localisation of atherosclerosis and NIH, highlight the importance of flow conditions and oxygen flux into the arterial wall on the development of NIH. Coppola and Caro, ${ }^{21}$ citing Tarbell and the link between a local lack of oxygen and both atherosclerosis and NIH, used CFD to examine

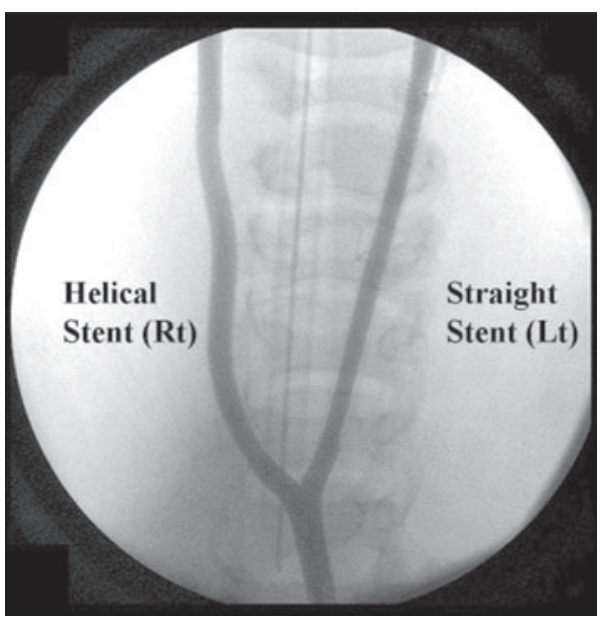

FIGURE 10. Angiograph showing the BioMimics 3D helical stent and the conventional straight stent inserted in the contralateral (left) and common carotid artery (right) respectively. ${ }^{130}$ Reproduced with permission from Veryan Medical Ltd.

the effects of arterial three-dimensionality on the distribution of WSS a the mass transport of oxygen from the blood flow into the arterial wall in a U-bend by modelling the blood vessels as either a cylindrical or helical conduit. It was shown that a helical geometry can reduce both the range and extent of low WSS regions and substantially increase the oxygen flux through the walls.

Shinke et al. ${ }^{130}$ presented results from a pilot porcine trial where two pigs were implanted with a conventional stent in one common carotid artery and the BioMimics 3D helical stent in the contralateral artery, as shown in the angiograph in Fig. 10. Comparisons were made between the histological sections taken at three locations in the two arteries, as shown in Fig. 11. As can be seen from these sections the extent of $\mathrm{NIH}$ with the helical stent was far less than with the conventional one and thus it was concluded that the helical stent's improved flow regime helped in minimising NIH.

The in vivo results from this porcine study were compared with CFD predictions by Coppola and Caro $^{22}$ and the effects of varying the geometrical parameters, i.e., the amplitude and frequency of the helical shape, on the flow pattern, WSS, and oxygen flux to the arterial wall were studied. It was expected that the increased mixing effects of the geometry-induced secondary flows would modify the distribution of WSS and produce higher oxygen flux levels to the arterial wall. Results showed that increasing the amplitude of the helical geometry increased the WSS and oxygen flux to the vessel wall, and that increasing the frequency increased the WSS but had no effect on the oxygen flux. ${ }^{22}$ Oddly, the results indicated that the inner curvature
1047

1048

1049

1050

1051

1052

1053

1054

1055

1056

1057

1058

1059

1060

1061

1062

1063

1064

1065

1066

1067

1068

1069

1070

1071

1072

1073

1074

1075

1076

1077

1078

1079

1080 
(a)

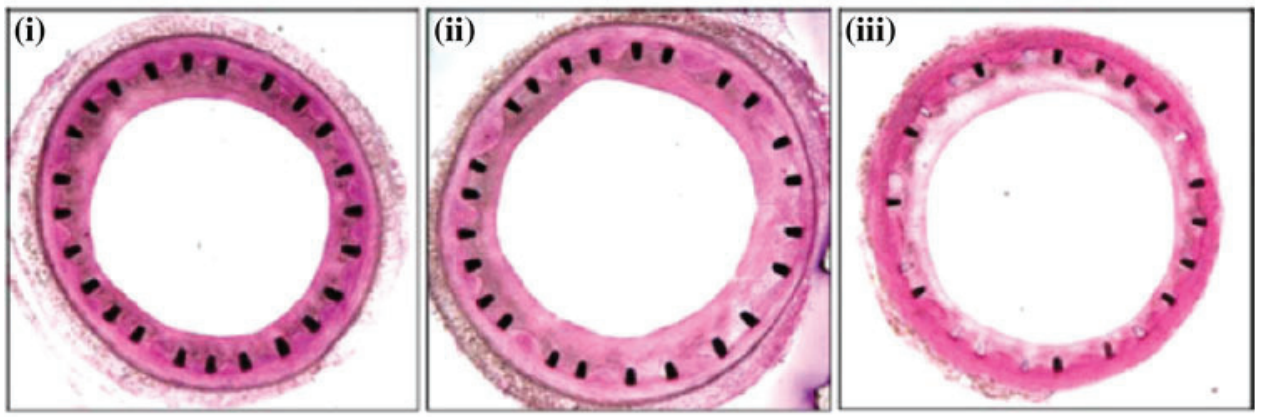

(b)

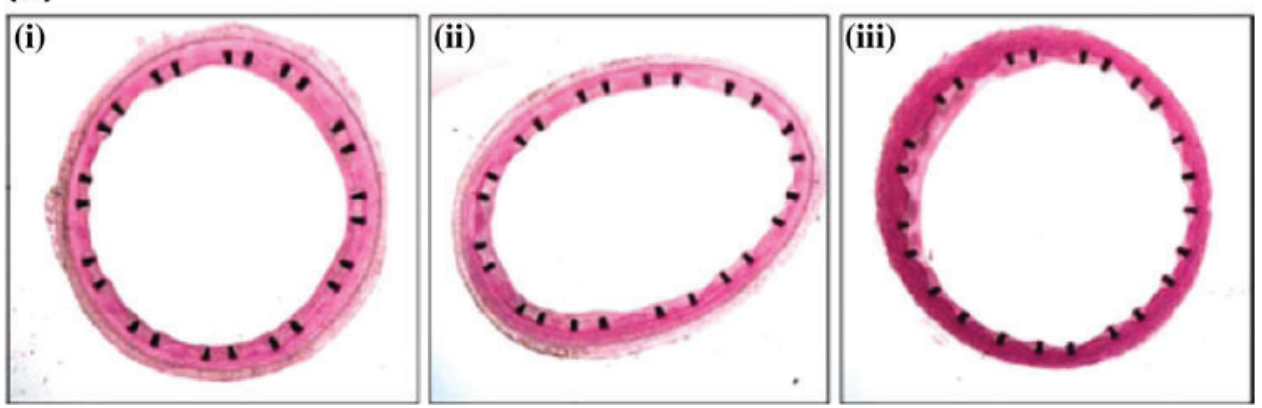

FIGURE 11. Histological sections of the stented arteries one month post implantation. The conventional straight stent is shown in (a) and the BioMimics 3D helical stent in (b). (i), (ii) and (iii) correspond to locations proximal, middle and distal to the stented sections respectively. ${ }^{130}$ Reproduced with permission from Veryan Medical Ltd.

1081 1082 1083 1084 1085 1086 1087 1088 1089 1090 1091 1092 1093 1094 1095 regions of the helical model are exposed to lower oxygen flux than in the corresponding straight stent case, and yet the development of NIH is lower in these regions, as shown by the porcine trial. The reasons for this were inconclusive; however, the overall results of the study were positive.

Cookson et al. ${ }^{20}$ conducted a CFD investigation of the mixing behaviour of a small amplitude helical pipe incorporating two different helical geometries, as shown in Fig. 12. Helix A has an amplitude of 0.2 times the diameter of the pipe and Helix B has an amplitude of 0.5 times the diameter. This investigation was based on the hypothesis that increased mixing, induced by helical geometries, reduced thrombosis in grafts incorporating SMAHT and that by joining together two helical geometries of different amplitudes the mixing effect could be enhanced further without an excessive pressure loss across the device. This study followed on from a previous numerical study of single helical geometries by Cookson et al. ${ }^{19}$ The results of the investigation indicated that the mixing effect was improved upon in the combined helical geometry in comparison with the single helical geometry and that the pressure drop was found to be less in the combined helical geometry. These results show a possible improvement in the original SMAHT design on which SwirlGraft and the BioMimics 3D helical stent are based.

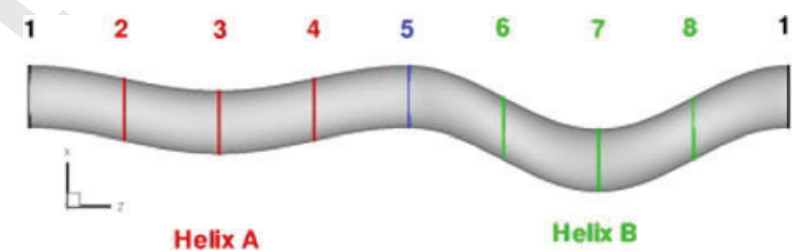

FIGURE 12. Diagram of the helical geometry employed by Cookson et al. ${ }^{20}$ in a CFD analysis of the mixing behaviour in a helical pipe with two different helical geometries.

Vascular Flow Technologies Ltd. Stent

The BioMimics 3D helical stent induces a helical flow by imposing a helical geometry on the treated artery, while another stent technology, currently in development at Vascular Flow Technologies Ltd (VFT) based in Dundee, Scotland, induces helical flow through the use of a helical ridge placed on the inner surface of the stent. VFT (formerly Tayside Flow Technologies) is a spin-out company set up in 1998 from Tayside University Hospitals NHS Trust. The stent technology being developed by VFT is based on research by Stonebridge et al. ${ }^{139-141}$ into the naturally occurring helical flow found in studies of the cardiovascular system using Doppler ultrasound, as mentioned previously. The benefits of helical flow, discussed earlier, led VFT to design a bypass graft,
1110 1111 1112 1113 1114 1115 1116 1117 1118 1119 1120 1121

1122

1123 

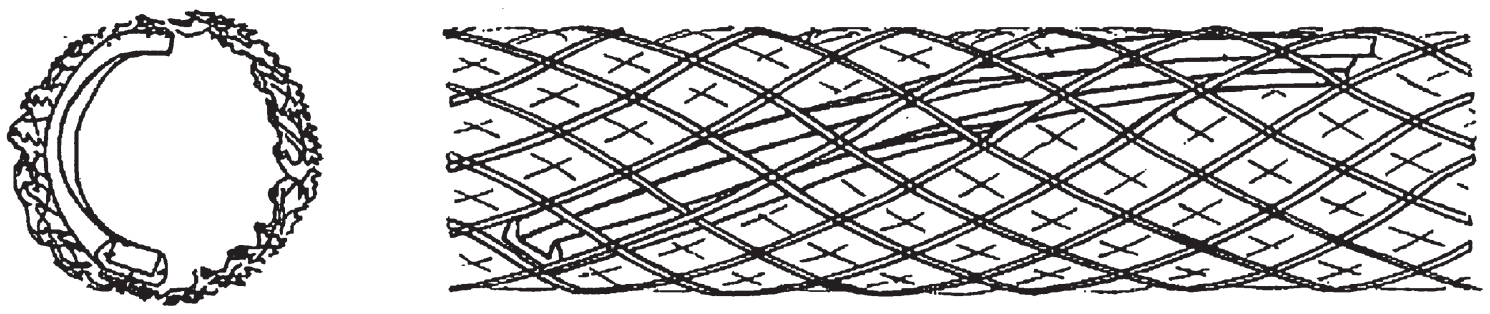

FIGURE 13. Axial and longitudinal views of the proposed helical-ridge insert for stents, adapted from European Patent EP1314406 (B1). ${ }^{65}$

1124 which was similar to SwirlGraft in its goal is to induce helical flow; however, instead of shaping the graft in a helical form which could be lost on implantation, this bypass graft incorporated a helical ridge at the distal end of the graft, which restored helical flow. Early clinical results from a first-in-man study were presented by Vermassen and Stonebridge ${ }^{150}$ in which 40 patients with peripheral arterial disease had the graft implanted. 10 patients were assessed for the presence of helical flow at 6 months and in all 10 helical flow was evident, confirming that the graft induced helical flow. In addition, a patency-rate of $88 \%$ at 1 year follow-up was found for the 40 patients treated. ${ }^{150}$

The company is currently developing a helical-ridge insert for stents, similar to the graft design, in order to induce helical flow in a stented artery. Two patents which have been filed give some details of this technology: European Patent EP1314406 (B1) ${ }^{65}$ and US Patent US7721767 (B2). ${ }^{64}$ The former describes a partially helical-shaped ridge insert for a stent as shown in Fig. 13, while the latter gives details of a method for determining the helix angle of a helical formation for a conduit.

A conduit, as described in the US Patent, includes natural blood-flow tubing, stents, and artificial industrial equipment, e.g., a hose or pipe. ${ }^{64}$ The method described in this patent allows the determination of the optimum helix angle through the use of two characteristic curves. As shown in Fig. 14, for a given mass flow rate in a given conduit the experimentally determined non-dimensional pressure drop and turbulent kinetic energy are plotted against the helix angle. The optimum helix angle would normally correspond to the angle at which the non-dimensional pressure drop and the non-dimensional turbulent kinetic energy are equal to zero, in this case at approximately 7.5 degrees (notated as 52 in Fig. 14); however, this may not always be the case. ${ }^{64}$

In a preclinical porcine study by Houston et al., ${ }^{62}$ an unmodified control stent and a modified stent incorporating the helical-ridge insert were compared in a 45 day carotid cuff stenosis model. The cuff model is

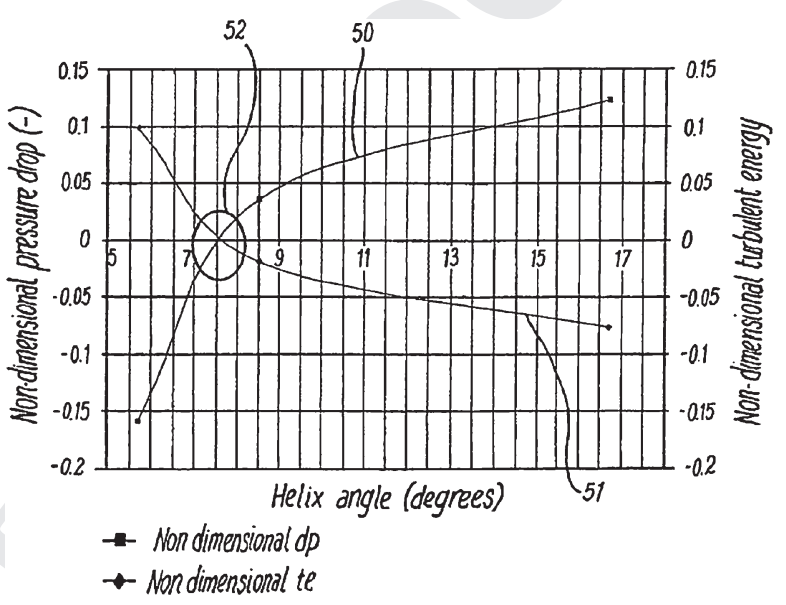

FIGURE 14. Graph taken from US Patent US7721767. The variation of non-dimensional pressure drop with the helix angle is notated as $\mathbf{5 0}$ and the variation of non-dimensional turbulent kinetic energy with the helix angle is notated as 51 . The helix angle when both variables are equal to zero is notated as $52 .{ }^{64}$

designed to mimic lesions that may occur downstream of a stent and to induce cell proliferation and ECM synthesis, both of which contribute to neointimal thickening. There was a statistically significant reduction in intima/media ratios distal to the implanted region in the modified stent porcine models, with a high ratio indicating significant neointimal thickening, in comparison with the control stent porcine models. Using Doppler ultrasound it was confirmed that the modified stent maintained the natural helical flow within the arteries of all eight pigs, whereas, the control stent did not. An idealised plain-wall tube was compared with a tube with a helical ridge using CFD and results obtained predicted a reduction in turbulent kinetic energy downstream of a $50 \%$ stenosis in the helical-ridge model.

\section{DISCUSSION}

There are many factors which influence the biological processes that can result in ISR. The local hemodynamics 
1185 is one of the factors that can be controlled to some degree 1186 by stent design. The ARED flow divider demonstrated 1187 that by increasing the blood flow velocity within a stented 1188 region, NIH could be reduced. Helical flow has been 1189 shown to exist in healthy arteries, although its implica1190 tions within the cardiovascular system are currently not 1191 fully understood. Through human, animal, in vitro and 1192 CFD studies helical flow has been shown to have bene1193 ficial hemodynamic characteristics in terms of inhibiting 1194 thrombus formation, inflammation and NIH in vascular 1195 grafts. Helical-flow-inducing technology is now being 1196 transferred over to the stent market to help reduce ISR 1197 rates. The theoretical benefits of this technology com1198 pared with current stent designs are greater mixing of particle trajectories, increased rotationally-induced stability, and reduced turbulence, stagnation zones, lengths of recirculation zones and near-wall particle residence times. Helical flow has also been shown to reduce both the range and extent of low WSS regions and substantially increase the oxygen flux through the arterial walls which could help minimise NIH. Both OSI and low WSS have been implicated in increased NIH and the hindering of re-endothelialisation. Helical flow has the benefit of reducing OSI and increasing the average WSS within the stented region. With these beneficial hemodynamic characteristics and their recognised effects on the biological processes post stent implantation, ISR rates could be reduced.

Some concerns highlighted with helical flow were an increase in pressure drop across a segment with helical flow compared with normal flow and low flow velocity concentrated in one area. One other issue is the mechanical stress levels imposed on an implanted artery which directly affect the amount of injury inflicted on the arterial wall. This is a concern for both helical-flowinducing devices presented in this paper. The BioMimics 3D helical stent can impose a severe geometric change on an artery and thus, could cause more damage to the arterial wall than a contemporary stent which conforms to the implanted artery. This issue has been addressed to an extent with tapered radial stiffness and collinear stent ends. The VFT helical-ridge insert could also have issues with stiffening of the stent caused by the ridge insert. This depends on the properties of the insert material and the manner in which it is fixed to the stent platform. To the best of the authors' knowledge there is no information available in the literature on the stress levels imposed by either designs and this could be an avenue for further study.

Clearly, more research into the nature of blood flow which occurs naturally in healthy arteries and ways to imitate it is needed, and at present is certainly gaining interest. Both helical stent technologies, which through the principles of biomimicry embrace the natural geometrical characteristics of the vascular system, are promising in the goal of reducing NIH. The BioMimics 3D helical stent itself is initially being targeted at the peripheral stent market. Veryan Medical have commenced a first-in-human and CE mark study at Herz Zentrum in Bad Krozingen, Germany under Professor Thomas Zeller. The VFT helical-ridge insert is still in development, is described as being potentially complimentary to DES technology, and is initially targeted at the peripheral stent market, with an expected date for securing the CE mark and FDA approval during the third quarter of 2012. ${ }^{104}$

\section{CONCLUSION}

1251

In an editorial by Richter and Edelman, ${ }^{113}$ the argument is presented that cardiology is flow. From inception, the cardiovascular system, and in particular the heart, develops in form and function as a flow system governed by blood-flow characteristics. This system is then continually modified according to the flow demands placed upon it throughout the body. Given that atherosclerosis, a disease affecting this flow system, has been proven to be initiated by endothelial dysfunction in areas of flow disturbance, the idea of the end goal of angioplasty being simply the displacement of a lesion and the re-establishment of flow might not be enough. The novel devices presented here look beyond this and concentrate on encouraging beneficial flow which can use the arterial-wall cells' natural responses to hemodynamics to aid in the healing of the stented region, potentially reducing ISR rates.

\section{ACKNOWLEDGMENTS}

The first author would like to express his appreciation to the ABBEST PhD Scholarship Programme at Dublin Institute of Technology for its support of this research.

\section{REFERENCES}

${ }^{1}$ Anderson, J. M., A. Rodriguez, and D. T. Chang. Foreign body reaction to biomaterials. Semin. Immunol. 20(2):86-100, 2008.

${ }^{2}$ Bassiouny, H. S., R. H. Song, H. Kocharyan, E. Kins, and S. Glagov. Low flow enhances platelet activation after acute experimental arterial injury. J. Vasc. Surg. 27(5):910-918, 1998.

${ }^{3}$ Bassiouny, H. S., S. White, S. Glagov, E. Choi, D. P. Giddens, and C. K. Zarins. Anastomotic intimal hyperplasia: mechanical injury or flow induced. J. Vasc. Surg. 15(4):708-716, 1992.
1278

1279

1280

1281

1282

1283

1284

1285

1286

1287

1288 
${ }^{4}$ Bayes-Genis, A., A. R. Camrud, M. Jorgenson, J. Donovan, K. L. Shogren, D. R. Holmes, Jr., et al. Pressure rinsing of coronary stents immediately before implantation reduces inflammation and neointimal hyperplasia. J. Am. Coll. Cardiol. 38(2):562-568, 2001.

${ }^{5}$ Beijk, M. A. M., M. Klomp, N. J. W. Verouden, N. van Geloven, K. T. Koch, J. P. S. Henriques, et al. Genous endothelial progenitor cell capturing stent versus the Taxus Liberté stent in patients with de novo coronary lesions with a high-risk of coronary restenosis: a randomized, single-centre, pilot study. Eur. Heart J. 31(9):1055-1064, 2009.

${ }^{6}$ Bhargava, B., N. K. Reddy, G. Karthikeyan, R. Raju, S. Mishra, S. Singh, et al. A novel paclitaxel-eluting porous carbon-carbon nanoparticle coated, nonpolymeric cobalt-chromium stent: evaluation in a porcine model. Catheter. Cardiovasc. Interv. 67(5):698-702, 2006.

${ }^{7}$ Brecher, G. A. Experimental evidence of ventricular diastolic suction. Circ. Res. 4(5):513-518, 1956.

${ }^{8}$ Carlier, S. G., L. C. A. van Damme, C. P. Blommerde, J. J. Wentzel, G. van Langehove, S. Verheye, et al. Augmentation of wall shear stress inhibits neointimal hyperplasia after stent implantation: inhibition through reduction of inflammation? Circulation 107(21):27412746, 2003.

${ }^{9}$ Caro, C. G. The dispersion of indicator flowing through simplified models of the circulation and its relevance to velocity profile in blood vessels. J. Physiol. 185(3):501$519,1966$.

${ }^{10}$ Caro, C. G., N. J. Cheshire, and N. Watkins. Preliminary comparative study of small amplitude helical and conventional ePTFE arteriovenous shunts in pigs. J. R. Soc. Interface 2(3):261-266, 2005.

${ }^{11}$ Caro, C. G., D. J. Doorly, M. Tarnawski, K. T. Scott, Q. Long, and C. L. Dumoulin. Non-planar curvature and branching of arteries and non-planar-type flow. Proc. Math. Phys. Eng. Sci. 452(1944):185-197, 1996.

${ }^{12}$ Caro, C., J. Fitz-Gerald, and R. Schroter. Arterial wall shear and distribution of early atheroma in man. Nature 13(223): 1159-1160, 1969.

${ }^{13}$ Chandran, K. B., A. P. Yoganathan, and S. E. Rittgers. Biofluid Mechanics: The Human Circulation (1st ed.). Boca Raton: CRC Press, 2006.

${ }^{14}$ Chatzizisis, Y. S., A. U. Coskun, M. Jonas, E. R. Edelman, C. L. Feldman, and P. H. Stone. Role of endothelial shear stress in the natural history of coronary atherosclerosis and vascular remodeling: molecular, cellular, and vascular behavior. J. Am. Coll. Cardiol. 49(25):2379-2393, 2007.

${ }^{15}$ Chen, Z., Y. Fan, X. Deng, and Z. Xu. Swirling flow can suppress flow disturbances in endovascular stents: a numerical study. ASAIO J. 55(6):543-549, 2009. doi: 10.1097/MAT.0b013e3181b78e46.

${ }^{16}$ Chen, H. Y., J. Hermiller, A. K. Sinha, M. Sturek, L. Zhu, and G. S. Kassab. Effects of stent sizing on endothelial and vessel wall stress: potential mechanisms for in-stent restenosis. J. Appl. Physiol. 106(5):1686-1691, 2009.

${ }^{17}$ Cheng, C., D. Tempel, R. van Haperen, A. van der Baan, F. Grosveld, M. J. A. P. Daemen, et al. Atherosclerotic lesion size and vulnerability are determined by patterns of fluid shear stress. Circulation 113(23):2744-2753, 2006.

${ }^{18}$ Chiastra, C., S. Morlacchi, S. Pereira, G. Dubini, and F. Migliavacca. Computational fluid dynamics of stented coronary bifurcations studied with a hybrid discretization method. Eur. J. Mech. B 35:76-84, 2012.
${ }^{19}$ Cookson, A., D. Doorly, and S. Sherwin. Mixing through stirring of steady flow in small amplitude helical tubes. Ann. Biomed. Eng. 37(4):710-721, 2009.

${ }^{20}$ Cookson, A. N., D. J. Doorly, and S. J. Sherwin. Using coordinate transformation of Navier-Stokes equations to solve flow in multiple helical geometries. J. Comput. Appl. Math. 234(7):2069-2079, 2010.

${ }^{21}$ Coppola, G., and C. Caro. Oxygen mass transfer in a model three-dimensional artery. J. R. Soc. Interface 5(26):1067-1075, 2008.

${ }^{22}$ Coppola, G., and C. Caro. Arterial geometry, flow pattern, wall shear and mass transport: potential physiological significance. J. R. Soc. Interface 6(35):519-528, 2009.

${ }^{23}$ Coughlin, M. F., and G. W. Schmid-Schönbein. Pseudopod Projection and Cell Spreading of Passive Leukocytes in Response to Fluid Shear Stress. Biophys. J . 87(3):20352042, 2004.

${ }^{24}$ DePaola, N., M. Gimbrone, P. Davies, and C. Dewey. Vascular endothelium responds to fluid shear stress gradients [published erratum appears in Arterioscler. Thromb. 13(3):465, 1993]. Arterioscl. Thromb. Vasc Biol. 12(11):1254-1257, 1992.

${ }^{25}$ Dichek, D., R. Neville, J. Zwiebel, S. Freeman, M. Leon, and W. Anderson. Seeding of intravascular stents with genetically engineered endothelial cells. Circulation 80(5):1347-1353, 1989.

${ }^{26}$ Ding, Z., and M. Friedman. Dynamics of human coronary arterial motion and its potential role in coronary atherogenesis. J. Biomech. Eng. 122(5):488-492, 2000.

${ }^{27}$ Ding, Z., and M. H. Friedman. Quantification of 3-D coronary arterial motion using clinical biplane cineangiograms. Int. J. Cardiac Imaging. 16(5):331-346, 2000.

${ }^{28}$ Ding, Z., H. Zhu, and M. Friedman. Coronary artery dynamics in vivo. Ann. Biomed. Eng. 30(4):419-429, 2002.

${ }^{29}$ Doorly, D. J., J. Peiró, S. J. Sherwin, O. Shah, C. Caro, M. Tarnawski, et al. (eds.). Helix and model graft flows: MRI measurement and CFD simulations. In: Proceedings of the ASME FED Meeting, 1997.

${ }^{30}$ Doorly, D. J., S. J. Sherwin, P. T. Franke, and J. Peiró. Vortical flow structure identification and flow transport in arteries. Comput. Methods Biomech. Biomed. Eng. 5(3):261, 2002

${ }^{31}$ Dotter, C. T., and M. P. Judkins. Transluminal treatment of arteriosclerotic obstruction: description of a new technic and a preliminary report of its application. Circulation 30(5):654-670, 1964.

${ }^{32}$ Dumoulin, C., and B. Cochelin. Mechanical behaviour modelling of balloon-expandable stents. J. Biomech. 33(11):1461-1470, 2000.

${ }^{33}$ Duraiswamy, N., J. M. Cesar, R. T. Schoephoerster, and J. E. Moore. Effects of stent geometry on local flow dynamics and resulting platelet deposition in an in vitro model. Biorheology 45(5):547-562, 2008.

${ }^{34}$ Duraiswamy, N., R. T. Schoephoerster, and J. E. Moore. Comparison of near-wall hemodynamic parameters in stented artery models. J. Biomech. Eng. 131(6):061006, 2009.

${ }^{35}$ Esmon, C. T. Inflammation and thrombosis. J. Thromb. Haemost. 1(7):1343-1348, 2003.

${ }^{36}$ Farb, A., G. Sangiorgi, A. J. Carter, V. M. Walley, W. D. Edwards, R. S. Schwartz, et al. Pathology of acute and chronic coronary stenting in humans. Circulation 99(1):44-52, 1999.

${ }^{37}$ Fischman, D. L., M. B. Leon, D. S. Baim, R. A. Schatz, M. P. Savage, I. Penn, et al. A randomized comparison of 
coronary-stent placement and balloon angioplasty in the treatment of coronary artery disease. New Engl. J. Med. 331(8):496-501, 1994.

${ }^{38}$ Frazin, L. J., G. Lanza, M. Vonesh, F. Khasho, C. Spitzzeri, $\mathrm{S}$. McGee, et al. Functional chiral asymmetry in descending thoracic aorta. Circulation 82(6):1985-1994, 1990.

${ }^{39}$ Frazin, L. J., M. J. Vonesh, K. B. Chandran, T. Shipkowitz, A. S. Yaacoub, and D. D. McPherson. Confirmation and initial documentation of thoracic and abdominal aortic helical flow: an ultrasound study. ASAIO J. 42(6):951-956, 1996.

${ }^{40}$ Fukuda, S., T. Yasu, D. N. Predescu, and G. W. SchmidSchönbein. Mechanisms for regulation of fluid shear stress response in circulating leukocytes. Circ. Res. 86(1):e13e18, 2000.

${ }^{41}$ Gaglia, Jr., M. A., R. Torguson, Z. Xue, M. A. Gonzalez, S. D. Collins, I. Ben-Dor, et al. Insurance type influences the use of drug-eluting stents. JACC: Cardiovasc. Interv. 3(7):773-779, 2010

${ }^{42}$ Garg, S., and P. W. Serruys. Coronary stents: current status. J. Am. Coll. Cardiol. 56(10 Suppl):S1-S42, 2010.

${ }^{43}$ Garg, S., and P. W. Serruys. Coronary stents: looking forward. J. Am. Coll. Cardiol. 56(10 Suppl):S43-S78, 2010.

${ }^{44}$ Geary, R., and A. Clowes. Epidemiology and pathogenesis of restenosis. In: Essentials of Restenosis for the Interventional Cardiologist, edited by H. J. Duckers, E. G. Nabel, and P. W. Serruys. Totowa: Humana Press, 2007.

${ }^{45}$ Geary, R., T. Kohler, S. Vergel, T. Kirkman, and A. Clowes. Time course of flow-induced smooth muscle cell proliferation and intimal thickening in endothelialized baboon vascular grafts. Circ. Res. 74(1):14-23, 1994.

${ }^{46}$ Gorbet, M. B., and M. V. Sefton. Biomaterial-associated thrombosis: roles of coagulation factors, complement, platelets and leukocytes. Biomaterials 25(26):5681-5703, 2004.

${ }^{47}$ Grigioni, M., C. Daniele, U. Morbiducci, C. Del Gaudio, G. D'Avenio, A. Balducci, et al. A mathematical description of blood spiral flow in vessels: application to a numerical study of flow in arterial bending. J. Biomech. 38(7):1375-1386, 2005.

${ }^{48}$ Grotendorst, G. R., T. Chang, H. E. J. Seppä, H. K. Kleinman, and G. R. Martin. Platelet-derived growth factor is a chemoattractant for vascular smooth muscle cells. J. Cell. Physiol. 113(2):261-266, 1982.

${ }^{49}$ Grüntzig, A. Transluminal dilation of coronary-artery stenosis. The Lancet. 311(8058):263, 1978.

${ }^{50}$ Grüntzig, A., and D. Kumpe. Technique of percutaneous transluminal angioplasty with the Gruntzig ballon catheter. Am. J. Roentgenol. 132(4):547-552, 1979.

${ }^{51}$ Grüntzig, A., W. Vetter, B. Meier, U. Kuhlmann, U. Lüolf, and W. Siegenthaler. Treatment of renovascular hypertension with percutaneous transluminal dilation of a renal-artery stenosis. The Lancet. 311(8068):801-802, 1978.

${ }^{52}$ Gyongyosi, M., P. Yang, A. Khorsand, D. Glogar, On behalf of the Austrian Wiktor Stent Study Group, European Paragon Stent Investigators. Longitudinal straightening effect of stents is an additional predictor for major adverse cardiac events. J. Am. Coll. Cardiol. 35(6):15801589,2000

${ }^{53}$ Han, C. I., G. R. Campbell, and J. H. Campbell. Circulating bone marrow cells can contribute to neointimal formation. J. Vasc. Res. 38(2):113-119, 2001.
${ }^{54}$ Harnek, J., E. Zoucas, E. Carlemalm, and W. Cwikiel. Differences in endothelial injury after balloon angioplasty, insertion of balloon-expanded stents or release of selfexpanding stents: an electron microscopic experimental study. Cardiovasc. Interv. Radiol. 22(1):56-61, 1999.

${ }^{55}$ Haruguchi, H., and S. Teraoka. Intimal hyperplasia and hemodynamic factors in arterial bypass and arteriovenous grafts: a review. J. Artif. Organs 6(4):227-235, 2003.

${ }^{56}$ Haude, M., R. Erbel, H. Issa, and J. Meyer J. Quantitative analysis of elastic recoil after balloon angioplasty and after intracoronary implantation of balloon-expandable Palmaz-Schatz stents. J. Am. Coll. Cardiol. 21(1):26-34, 1993.

${ }^{57} \mathrm{He}$, Y., N. Duraiswamy, A. O. Frank, and J. J. E. Moore. blood flow in stented arteries: a parametric comparison of strut design patterns in three dimensions. J. Biomech. Eng. 127(4):637-647, 2005.

${ }^{58}$ Helmlinger, G., R. V. Geifer, S. Schreck, and R. M. Nerem. Effects of pulsatile flow on cultured vascular endothelial cell morphology. J. Biomech. Eng. 113(2):123$131,1991$.

${ }^{59}$ Hofer, M., G. Rappitsch, K. Perktold, W. Trubel, and H. Schima. Numerical study of wall mechanics and fluid dynamics in end-to-side anastomoses and correlation to intimal hyperplasia. J. Biomech. 29(10):1297-1308, 1996.

${ }^{60}$ Holmes, Jr., D. R., D. J. Kereiakes, S. Garg, P. W. Serruys, G. J. Dehmer, S. G. Ellis, et al. Stent thrombosis. J. Am. Coll. Cardiol. 56(17):1357-1365, 2010.

${ }^{61}$ Hong, M.-K., S.-W. Park, C. W. Lee, D.-H. Kang, J.-K. Song, J-. J. Kim, et al. Long-term outcomes of minor plaque prolapsed within stents documented with intravascular ultrasound. Catheter. Cardiovasc. Interv. 51(1):22-26, 2000

${ }^{62}$ Houston, J. G., M. Bonneau, C. Kang, P. A. Stonebridge, and J. Dick. Reducing intimal thickening and arterial wall stresses downstream to a spiral flow inducing stent in a carotid arterial stenosis porcine model. CIRSE 2008, Copenhagen, Denmark, 2008.

${ }^{63}$ Houston, J. G., S. J. Gandy, W. Milne, J. B. C. Dick, J. J. F. Belch, and P. A. Stonebridge. Spiral laminar flow in the abdominal aorta: a predictor of renal impairment deterioration in patients with renal artery stenosis? Nephrol. Dialysis Transplant. 19(7):1786-1791, 2004.

${ }^{64}$ Houston, J. G., R. Hood, P. A. Stonebridge, and A. Thomson (inventors). Tayside Flow Technologies Ltd, Assignee. Method of Determining the Helix Angle of a Helical Formation for a Conduit. United States of America Patent, US7721767B2, 2010.

${ }^{65}$ Houston, J. G., P. A. Stonebridge, J. Dick, R. Hood, A. Johnstone, C. Sarran, et al. (inventors). An insert for a Stent 2007.

${ }^{66}$ Hsu, P-. P., S. Li, Y.-S. Li, S. Usami, A. Ratcliffe, X. Wang, et al. Effects of flow patterns on endothelial cell migration into a zone of mechanical denudation. Biochem. Biophys. Res. Commun. 285(3):751-759, 2001.

${ }^{67}$ Huijbregts, H. J. T. A. M., P. J. Blankestijn, C. G. Caro, N. J. W. Cheshire, M. T. C. Hoedt, R. P. Tutein Nolthenius, et al. A helical PTFE arteriovenous access graft to swirl flow across the distal anastomosis: results of a preliminary clinical study. Eur. J. Vasc. Endovasc. Surg. 33(4):472-475, 2007.

${ }^{68}$ Inoue, T., K. Croce, T. Morooka, M. Sakuma, K. Node, and D. I. Simon. Vascular inflammation and repair: implications for re-endothelialization, restenosis, and stent thrombosis. J. Am. Coll. Cardiol. Interv. 4(10):10571066, 2011. 
${ }^{69}$ Inoue, T., M. Sata, Y. Hikichi, R. Sohma, D. Fukuda, T. Uchida, et al. Mobilization of CD34-positive bone marrow-derived cells after coronary stent implantation. Circulation 115(5):553-561, 2007.

${ }^{70}$ Jang, I. -K., G. Tearney, and B. Bouma. Visualization of tissue prolapse between coronary stent struts by optical coherence tomography. Circulation 104(22):2754, 2001.

${ }^{71}$ Jiménez, J., and P. F. Davies. Hemodynamically driven stent strut design. Ann. Biomed. Eng. 37(8):1483-1494, 2009.

${ }^{72}$ Joner, M., A. V. Finn, A. Farb, E. K. Mont, F. D. Kolodgie, E. Ladich, et al. Pathology of drug-eluting stents in humans: delayed healing and late thrombotic risk. J. Am. Coll. Cardiol. 48(1):193-202, 2006.

${ }^{73}$ Joner, M., G. Nakazawa, A. V. Finn, S. C. Quee, L. Coleman, E. Acampado, et al. Endothelial cell recovery between comparator polymer-based drug-eluting stents. J. Am. Coll. Cardiol. 52(5):333-342, 2008.

${ }^{74}$ Kastrati, A., J. Dirschinger, P. Boekstegers, S. Elezi, H. Schühlen, J. Pache, et al. Influence of stent design on 1-year outcome after coronary stent placement: a randomized comparison of five stent types in 1,147 unselected patients. Catheter. Cardiovasc. Interv. 50(3):290-297, 2000.

${ }^{75}$ Kilner, P., G. Yang, R. Mohiaddin, D. Firmin, and D. Longmore. Helical and retrograde secondary flow patterns in the aortic arch studied by three-directional magnetic resonance velocity mapping. Circulation 88(5):22352247, 1993.

${ }^{76}$ Kleinstreuer, C., S. Hyun, J. R. Buchanan, P. W. Longest, J. P. Archie, and G. A. Truskey. Hemodynamic parameters and early intimal thickening in branching blood vessels. Crit. Rev. Biomed. Eng. 29(1):1-64, 2001.

${ }^{77}$ Krams, R. ARED Flow Divider. Personal Communication, 2011.

${ }^{78}$ Krone, R. J., S. V. Rao, D. Dai, H. V. Anderson, E. D. Peterson, M. A. Brown, et al. Acceptance, panic, and partial recovery: the pattern of usage of drug-eluting stents after introduction in the U.S. (A report from the American College of Cardiology/National Cardiovascular Data Registry). JACC Cardiovasc. Interv. 3(9):902-910, 2010.

${ }^{79} \mathrm{Ku}$, D., D. Giddens, C. Zarins, and S. Glagov. Pulsatile flow and atherosclerosis in the human carotid bifurcation. Positive correlation between plaque location and low oscillating shear stress. Arterioscler. Thromb. Vasc. Biol. 5(3):293-302, 1985.

${ }^{80}$ LaDisa, J., L. Olson, H. Douglas, D. Warltier, J. Kersten, and P. Pagel. Alterations in regional vascular geometry produced by theoretical stent implantation influence distributions of wall shear stress: analysis of a curved coronary artery using 3D computational fluid dynamics modeling. Biomed. Eng. Online 5(1):40, 2006.

${ }^{81}$ LaDisa, Jr., J. F., L. E. Olson, I. Guler, D. A. Hettrick, S. H. Audi, J. R. Kersten, et al. Stent design properties and deployment ratio influence indexes of wall shear stress: a three-dimensional computational fluid dynamics investigation within a normal artery. J. Appl. Physiol. 97(1):424-430, 2004.

${ }^{82}$ LaDisa, J., L. Olson, D. Hettrick, D. Warltier, J. Kersten, and P. Pagel. Axial stent strut angle influences wall shear stress after stent implantation: analysis using 3D computational fluid dynamics models of stent foreshortening. Biomed. Eng. Online 4(1):59, 2005.

${ }^{83}$ Lee, E. S., M. P. Caldwell, A. S. Tretinyak, and S. M. Santilli. Supplemental oxygen controls cellular proliferation and anastomotic intimal hyperplasia at a vascular graftto-artery anastomosis in the rabbit. J. Vasc. Surg. 33(3):608613,2001

${ }^{84}$ Leung, D., S. Glagov, and M. Mathews. Cyclic stretching stimulates synthesis of matrix components by arterial smooth muscle cells in vitro. Science 191(4226):475-477, 1976.

${ }^{85} \mathrm{Li}$, Y., K. G. Neoh, and E.-T. Kang. Plasma protein adsorption and thrombus formation on surface functionalized polypyrrole with and without electrical stimulation. J. Colloid Interface Sci. 275(2):488-495, 2004.

${ }^{86}$ Liu, X., F. Pu, Y. Fan, X. Deng, D. Li, and S. Li. A numerical study on the flow of blood and the transport of LDL in the human aorta: the physiological significance of the helical flow in the aortic arch. Am. J. Physiol. Heart Circ. Physiol. 297(1):H163-H170, 2009.

${ }^{87}$ Malek, A. M., S. L. Alper, and S. Izumo. Hemodynamic shear stress and its role in atherosclerosis. J. Am. Med. Assoc. (JAMA) 282(21):2035-2042, 1999.

${ }^{88}$ Malek, A. M., and S. Izumo. Mechanism of endothelial cell shape change and cytoskeletal remodeling in response to fluid shear stress. J. Cell Sci. 109(4):713-726, 1996.

${ }^{89}$ Mallinger, F., and D. Drikakis. Laminar-to-turbulent transition in pulsatile flow through a stenosis. Biorheology. 39(3):437-441, 2002.

${ }^{90}$ Marinelli, R., B. Fuerst, H. Zee, A. McGinn, and W. Marinelli. The heart is not a pump: a refutation of the pressure propulsion premise of heart function. Front. Perspect. 5(1):15-24, 1995.

${ }^{91}$ Marinelli, R., D. G. Penney, W. Marinelli, and F. A. Baciewicz, Jr. Rotary motion in the heart and blood vessels: a review. J. Appl. Cardiol. 6(6):421-431, 1991.

${ }^{92}$ Martin, D. M., and F. J. Boyle. Drug-eluting stents for coronary artery disease: a review. Med. Eng. Phys. 33(2):148-163, 2010.

${ }^{93}$ Massai, D., G. Soloperto, D. Gallo, X. Y. Xu, and U. Morbiducci. Shear-induced platelet activation and its relationship with blood flow topology in a numerical model of stenosed carotid bifurcation. Eur. J. Mech. B 35:92-101, 2012.

${ }^{94}$ McLaren, M., and G. Kennedy. Endothelium II: inflammatory response. Surgery 23(1):1-6, 2005.

${ }^{95}$ Mehran, R., G. Dangas, A. S. Abizaid, G. S. Mintz, A. J. Lansky, L. F. Satler, et al. Angiographic patterns of in-stent restenosis : classification and implications for long-term outcome. Circulation 100(18):1872-1878, 1999.

${ }^{96}$ Moazzam, F., F. A. DeLano, B. W. Zweifach, and G. W. Schmid-Schönbein. The leukocyte response to fluid stress. Proc. Natl Acad. Sci. USA 94(10):5338-5343, 1997.

${ }^{97}$ Moore, J., J. Soares, and K. Rajagopal. Biodegradable Stents: biomechanical Modeling Challenges and Opportunities. Cardiovasc. Eng. Technol. 1(1):52-65, 2010.

${ }^{98}$ Morbiducci, U., R. Ponzini, M. Grigioni, and A. Redaelli. Helical flow as fluid dynamic signature for atherogenesis risk in aortocoronary bypass. A numeric study. J. Biomech. 40(3):519-534, 2007.

${ }^{99}$ Morbiducci, U., R. Ponzini, M. Nobili, D. Massai, F. M. Montevecchi, D. Bluestein, et al. Blood damage safety of prosthetic heart valves. Shear-induced platelet activation and local flow dynamics: a fluid-structure interaction approach. J. Biomech. 42(12):1952-1960, 2009.

${ }^{100}$ Morbiducci, U., R. Ponzini, G. Rizzo, M. Cadioli, A. Esposito, F. Montevecchi, et al. Mechanistic insight into the physiological relevance of helical blood flow in the human aorta: an in vivo study. Biomech. Model. Mechanobiol. 10(3):339-355, 2011. 
${ }^{101}$ Murphy, J., and F. Boyle. A numerical methodology to fully elucidate the altered wall shear stress in a stented coronary artery. Cardiovasc. Eng. Technol. 1(4):256-268, 2010.

${ }^{102}$ Nakamura, M., P. G. Yock, H. N. Bonneau, K. Kitamura, T. Aizawa, H. Tamai, et al. Impact of peri-stent remodeling on restenosis: a volumetric intravascular ultrasound study. Circulation 103(17):2130-2132, 2001.

${ }^{103}$ Nebeker, J. R., R. Virmani, C. L. Bennett, J. M. Hoffman, M. H. Samore, J. Alvarez, et al. Hypersensitivity cases associated with drug-eluting coronary stents: a review of available cases from the Research on Adverse Drug Events and Reports (RADAR) Project. J. Am. Coll. Cardiol. 47(1):175-181, 2006.

${ }^{104}$ Nelson, R. Spiral Flow. Personal Correspondence with author, 2011.

${ }^{105}$ Niccoli, G., G. A. Sgueglia, and F. Crea. The emerging role of allergic inflammation in adverse reactions after coronary stent implantation. Atherosclerosis. 217(1):70$71,2011$.

${ }^{106}$ Padfield, G. J., D. E. Newby, and N. L. Mills. Understanding the role of endothelial progenitor cells in percutaneous coronary intervention. J. Am. Coll. Cardiol. 55(15):1553-1565, 2010.

${ }^{107}$ Papafaklis, M. I., C. V. Bourantas, P. E. Theodorakis, C. S. Katsouras, D. I. Fotiadis, and L. K. Michalis Relationship of shear stress with in-stent restenosis: bare metal stenting and the effect of brachytherapy. Int J. Cardiol. 134(1):25-32, 2009.

${ }^{108}$ Papaharilaou, Y., D. J. Doorly, and S. J. Sherwin. The influence of out-of-plane geometry on pulsatile flow within a distal end-to-side anastomosis. J. Biomech. 35(9):12251239, 2002.

${ }^{109}$ Paul, M. C., and A. Larman. Investigation of spiral blood flow in a model of arterial stenosis. Med. Eng. Phys. 31(9):1195-1203, 2009.

${ }^{110}$ Phelps, J. E., and N. DePaola. Spatial variations in endothelial barrier function in disturbed flows in vitro. Am. J. Physiol. Heart Circ. Physiol. 278(2):H469-H476, 2000.

${ }^{111}$ Ponde, C. K., C. N. Aroney, P. T. McEniery, and J. H. N. Bett. Plaque prolapse between the struts of the intracoronary Palmaz-Schatz stent: report of two cases with a novel treatment of this unusual problem. Catheter. Cardiovasc. Diagn. 40(4):353-357, 1997.

${ }^{112}$ Pritchard, W. F., P. F. Davies, Z. Derafshi, D. C. Polacek, R. Tsao, R. O. Dull, et al. Effects of wall shear stress and fluid recirculation on the localization of circulating monocytes in a three-dimensional flow model. J. Biomech. 28(12):1459-1469, 1995.

${ }^{113}$ Richter, Y., and E. R. Edelman. Cardiology is flow. Circulation 113(23):2679-2682, 2006.

${ }^{114}$ Roger, V. L., A. S. Go, D. M. Lloyd-Jones, R. J. Adams, J. D. Berry, T. M. Brown, et al. Heart disease and stroke statistics - 2011 update: a report from the American Heart Association. Circulation 123(4):e18-e209, 2011.

${ }^{115}$ Rogers, C., and E. R. Edelman. Endovascular stent design dictates experimental restenosis and thrombosis. Circulation 91(12):2995-3001, 1995.

${ }^{116}$ Rogers, C., S. Parikh, P. Seifert, and E. R. Edelman. Endogenous cell seeding: remnant endothelium after stenting enhances vascular repair. Circulation 94(11):29092914, 1996.

${ }^{117}$ Rogers, C., D. Y. Tseng, J. C. Squire, and E. R. Edelman. Balloon-artery interactions during stent placement: a finite element analysis approach to pressure, compliance, and stent design as contributors to vascular injury. Circ. Res. 84(4):378-383, 1999.

${ }^{118}$ Rouleau, L., I. Copland, J.-C. Tardif, R. Mongrain, and R. Leask. Neutrophil adhesion on endothelial cells in a novel asymmetric stenosis model: effect of wall shear stress gradients. Ann. Biomed. Eng. 38(9):2791-2804, 2010.

${ }^{119}$ Rouleau, L., M. Farcas, J.-C. Tardif, R. Mongrain, and R. L. Leask. Endothelial cell morphologic response to asymmetric stenosis hemodynamics: effects of spatial wall shear stress gradients. J. Biomech. Eng. 132(8):081013, 2010.

${ }^{120}$ Rouleau, L., J. Rossi, and R. L. Leask. The response of human aortic endothelial cells in a stenotic hemodynamic environment: effect of duration, magnitude, and spatial gradients in wall shear stress. J. Biomech. Eng. 132(7):071015, 2010.

${ }^{121}$ Rubanyi, G. M. The role of endothelium in cardiovascular homeostasis and diseases. J. Cardiovasc. Pharmacol. 22:S1-S14, 1993.

${ }^{122}$ Sanmartín, M., J. Goicolea, C. García, J. García, A. Crespo, J. Rodríguez, et al. Influence of shear stress on in-stent restenosis: in vivo study using 3D reconstruction and computational fluid dynamics. Rev. Esp. Cardiol. 59(1):20-27, 2006.

${ }^{123}$ Scheinert, D., S. Scheinert, J. Sax, C. Piorkowski, S. Bräunlich, M. Ulrich, et al. Prevalence and clinical impact of stent fractures after femoropopliteal stenting. J. Am. Coll. Cardiol. 45(2):312-315, 2005.

${ }^{124}$ Schoephoerster, R., F. Oynes, G. Nunez, M. Kapadvanjwala, and M. Dewanjee. Effects of local geometry and fluid dynamics on regional platelet deposition on artificial surfaces. Arterioscl. Thromb. Vasc. Biol. 13(12):1806-1813, 1993.

${ }^{125}$ Segadal, L., and K. Matre. Blood velocity distribution in the human ascending aorta. Circulation 76(1):90-100, 1987.

${ }^{126}$ Serruys, P. W., P. de Jaegere, F. Kiemeneij, C. Macaya, W. Rutsch, G. Heyndrickx, et al. A comparison of balloon-expandable-stent implantation with balloon angioplasty in patients with coronary artery disease. N. Engl. J. Med. 331(8):489-495, 1994.

${ }^{127}$ Shi, Z.-D., G. Abraham, and J. M. Tarbell. Shear stress modulation of smooth muscle cell marker genes in 2-D and 3-D depends on mechanotransduction by heparan sulfate proteoglycans and ERK1/2. PLoS ONE 5(8):e12196, 2010.

${ }^{128}$ Shi, H.-J., A.-H. Cao, and G.-J. Teng. Seeding endothelial progenitor cells on a self-expanding metal stent: an in vitro study. J. Vasc. Interv. Radiol. 21(7):1061-1065, 2010.

${ }^{129}$ Shigematsu, K., H. Yasuhara, H. Shigematsu, and T. Muto. Direct and indirect effects of pulsatile shear stress on the smooth muscle cell. Int. Angiol. 19:39-46, 2000.

${ }^{130}$ Shinke, T., K. Robinson, M. G. Burke, P. Gilson, L. P. Mullins, N. O'Brien, et al. Abstract 6059: novel helical stent design elicits swirling blood flow pattern and inhibits neointima formation in porcine carotid arteries. Circulation 118:S1054, 2008.

${ }^{131}$ Simper, D., P. G. Stalboerger, C. J. Panetta, S. Wang, and N. M. Caplice. Smooth muscle progenitor cells in human blood. Circulation 106(10):1199-1204, 2002.

${ }^{132}$ Sprague, E. A., J. Luo, and J. C. Palmaz. Human aortic endothelial cell migration onto stent surfaces under static and flow conditions. J. Vasc. Interv. Radiol. 8(1):83-92, 1997. 
${ }^{133}$ Sprague, E. A., and J. C. Palmaz. A model system to assess key vascular responses to biomaterials. J. Endovasc. Ther. 12(5):594-604, 2005.

${ }^{134}$ Stergiopulos, N. Inventor Implant with deflector for intravascular dilation patent EP 0989830 B1, 2000.

${ }^{135}$ Sterpetti, A. V., A. Cucina, A. Fragale, S. Lepidi, A. Cavallaro, and L. Santoro-D'Angelo. Shear stress influences the release of platelet derived growth factor and basic fibroblast growth factor by arterial smooth muscle cells. Eur. J. Vasc. Surg. 8(2):138-142, 1994.

${ }^{136}$ Stone, P. H., A. U. Coskun, S. Kinlay, M. E. Clark, M. Sonka, A. Wahle, et al. Effect of endothelial shear stress on the progression of coronary artery disease, vascular remodeling, and in-stent restenosis in humans: in vivo 6month follow-up study. Circulation 108(4):438-444, 2003.

${ }^{137}$ Stone, G. W., J. W. Moses, S. G. Ellis, J. Schofer, K. D. Dawkins, M.-C. Morice, et al. Safety and efficacy of sirolimus- and paclitaxel-eluting coronary stents. N. Engl. J. Med. 356(10):998-1008, 2007.

${ }^{138}$ Stonebridge, P. A. Three-dimensional blood flow dynamics: spiral/helical laminar flow. Methodist DeBakey Cardiovasc. J. 7(1):21-26, 2011.

${ }^{139}$ Stonebridge, P. A., and C. M. Brophy. Spiral laminar flow in arteries? Lancet 338(8779):1360-1361, 1991.

${ }^{140}$ Stonebridge, P. A., C. Buckley, A. Thompson, J. Dick, G. Hunter, J. A. Chudek, et al. Non spiral and spiral (helical) flow patterns in stenoses. In vitro observations using spin and gradient echo magnetic resonance imaging (MRI) and computable fluid dynamics modeling. Int. Angiol. 23(3):276-283, 2004.

${ }^{141}$ Stonebridge, P. A., P. R. Hoskins, P. L. Allan, and J. F. Belch. Spiral laminar flow in vivo. Clin. Sci. 91(1):17-21, 1996.

${ }^{142}$ Sumagin, R., K. A. Lamkin-Kennard, and I. H. Sarelius. A Separate Role for ICAM-1 and Fluid Shear in Regulating Leukocyte Interactions with Straight Regions of Venular Wall and Venular Convergences. Microcirculation. 16(6):508-520, 2009.

${ }^{143}$ Suo, J. Investigation of blood flow patterns and hemodynamics in the human ascending aorta and major trucks of the right and left coronary arteries using magnetic resonance imaging and computational fluid dynamics. Georgia: Georgia Institute of Technology, 2005.

${ }^{144}$ Tarbell, J. M. Mass transport in arteries and the localization of atherosclerosis. Annu. Rev. Biomed. Eng. 5(1):79-118, 2003.

${ }^{145}$ Tardy, Y., N. Resnick, T. Nagel, M. A. Gimbrone, Jr., and C. F. Dewey, Jr. Shear stress gradients remodel endothelial monolayers in vitro via a cell proliferationmigration-loss cycle. Arterioscl. Thromb. Vasc Biol. 17(11):3102-3106, 1997.

${ }^{146}$ Texon, M. Hemodynamic basis of atherosclerosis with critique of the cholesterol-heart disease hypothesis. Cardiovasc. Eng. 1(1):57-58, 2001.
${ }^{147}$ Torrent-Guasp, F., M. Ballester, G. D. Buckberg, F. Carreras, A. Flotats, I. Carrio, et al. Spatial orientation of the ventricular muscle band: physiologic contribution and surgical implications. J. Thorac. Cardiovasc. Surg. 122(2):389-392, 2001.

${ }^{148}$ Ueba, H., M. Kawakami, and T. Yaginuma. Shear stress as an inhibitor of vascular smooth muscle cell proliferation: role of transforming growth factor-beta1 and tissuetype plasminogen activator. Arterioscl. Thromb. Vasc. Biol. 17(8):1512-1516, 1997.

${ }^{149}$ van der Giessen, W. J., A. M. Lincoff, R. S. Schwartz, H. M. M. van Beusekom, P. W. Serruys, D. R. Holmes, et al. Marked inflammatory sequelae to implantation of biodegradable and nonbiodegradable polymers in porcine coronary arteries. Circulation 94(7):1690-1697, 1996.

${ }^{150}$ Vermassen, F., and P. A. Stonebridge. Spiral laminar flow arterial grafts: improved early clinical results and theoretical basis. 36th Annual Symposium on Vascular and Endovascular Issues, 19 November 2008, New York, 2008.

${ }^{151}$ Virmani, R., G. Guagliumi, A. Farb, G. Musumeci, N. Grieco, T. Motta, et al. Localized hypersensitivity and late coronary thrombosis secondary to a sirolimus-eluting stent. Circulation 109(6):701-705, 2004.

${ }^{152}$ Wang, H., S. Yan, H. Chai, G. M. Riha, M. Li, Q. Yao, et al. Shear stress induces endothelial transdifferentiation from mouse smooth muscle cells. Biochem. Biophys. Res. Commun. 346(3):860-865, 2006.

${ }^{153}$ Wentzel, J. J., F. J. H. Gijsen, N. Stergiopulos, P. W. Serruys, C. J. Slager, and R. Krams. Shear stress, vascular remodeling and neointimal formation. J. Biomech. 36(5):681-688, 2003.

${ }^{154}$ Wentzel, J. J., R. Krams, J. C. H. Schuurbiers, J. A. Oomen, J. Kloet, W. J. van der Giessen, et al. Relationship between neointimal thickness and shear stress after wallstent implantation in human coronary arteries. Circulation 103(13):1740-1745, 2001.

${ }^{155}$ Whitcher, F. D. Simulation of in vivo loading conditions of nitinol vascular stent structures. Comput. Struct. 64(56):1005-1011, 1997.

${ }^{156}$ Windecker, S., I. Mayer, G. De Pasquale, W. Maier, O. Dirsch, P. De Groot, et al. Stent coating with titaniumnitride-oxide for reduction of neointimal hyperplasia. Circulation 104(8):928-933, 2001.

${ }^{157}$ Zabielski, L., and A. J. Mestel. Helical flow around arterial bends for varying body mass. J. Biomech. Eng. 122(2):135-142, 2000.

${ }^{158}$ Zhan, F., Y. Fan, and X. Deng. Swirling flow created in a glass tube suppressed platelet adhesion to the surface of the tube: its implication in the design of small-caliber arterial grafts. Thromb. Res. 125(5):413-418, 2010.

${ }^{159}$ Zheng, T., Y. Fan, Y. Xiong, W. Jiang, and X. Deng. Hemodynamic performance study on small diameter helical grafts. ASAIO J. 55(3):192-199, 2009. doi: 10.1097/MAT.0b013e31819b34f2.
1863

1864

1865

1866

1867

1868

1869

1870

1871

1872

1873

1874

1875

1876

1877

1878

1879

1880

1881

1882

1883

1884

1885

1886

1887

1888

1889

1890

1891

1892

1893

1894

1895

1896

1897

1898

1899

1900

1901

1902

1903

1904

1905

1906

1907

1908

1909

1910

1911

1912

1913

1914

1915

1916 